\title{
SOEP
}

SOEPpapers

SOEPpapers
on Multidisciplinary Panel Data Research

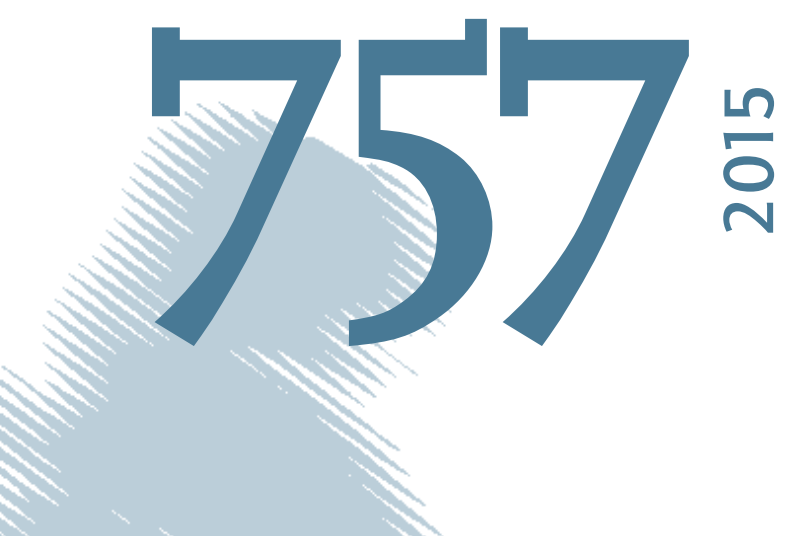

e

\section{Demand and Selection Effects in Supplemental Health Insurance in Germany}

Renate Lange, Jörg Schiller, Petra Steinorth 
This series presents research findings based either directly on data from the German SocioEconomic Panel study (SOEP) or using SOEP data as part of an internationally comparable data set (e.g. CNEF, ECHP, LIS, LWS, CHER/PACO). SOEP is a truly multidisciplinary household panel study covering a wide range of social and behavioral sciences: economics, sociology, psychology, survey methodology, econometrics and applied statistics, educational science, political science, public health, behavioral genetics, demography, geography, and sport science.

The decision to publish a submission in SOEPpapers is made by a board of editors chosen by the DIW Berlin to represent the wide range of disciplines covered by SOEP. There is no external referee process and papers are either accepted or rejected without revision. Papers appear in this series as works in progress and may also appear elsewhere. They often represent preliminary studies and are circulated to encourage discussion. Citation of such a paper should account for its provisional character. A revised version may be requested from the author directly.

Any opinions expressed in this series are those of the author(s) and not those of DIW Berlin. Research disseminated by DIW Berlin may include views on public policy issues, but the institute itself takes no institutional policy positions.

The SOEPpapers are available at http://www.diw.de/soeppapers

\section{Editors:}

Jan Goebel (Spatial Economics)

Martin Kroh (Political Science, Survey Methodology)

Carsten Schröder (Public Economics)

Jürgen Schupp (Sociology)

Conchita D'Ambrosio (Public Economics)

Denis Gerstorf (Psychology, DIW Research Director)

Elke Holst (Gender Studies, DIW Research Director)

Frauke Kreuter (Survey Methodology, DIW Research Fellow)

Frieder R. Lang (Psychology, DIW Research Fellow)

Jörg-Peter Schräpler (Survey Methodology, DIW Research Fellow)

Thomas Siedler (Empirical Economics)

C. Katharina Spieß (Education and Family Economics)

Gert G. Wagner (Social Sciences)

ISSN: 1864-6689 (online)

German Socio-Economic Panel Study (SOEP)

DIW Berlin

Mohrenstrasse 58

10117 Berlin, Germany

Contact: Uta Rahmann | soeppapers@diw.de 


\title{
Demand and Selection Effects in Supplemental Health Insurance in Germany
}

\author{
Renate Lange ${ }^{a}$, Jörg Schiller ${ }^{a, b}$ and Petra Steinorth ${ }^{c}$
}

\begin{abstract}
:
This paper empirically assesses the selection effects and determinants of the demand for supplemental health insurance that covers hospital and dental benefits in Germany. Our representative dataset provides doctor-diagnosed indicators of the individual's health status, risk attitude, demand for medical services and insurance purchases in other lines of insurance as well as rich demographic and socioeconomic information. Controlling for a wide range of individual preferences, we find evidence of adverse selection for individuals aged 65 and younger for hospital coverage despite initial individual underwriting by insurers. The reverse is true for individuals older than 65 ; individuals with supplemental hospital coverage are healthier on average. In addition, insurance affinity and income are the most important drivers of the demand for both types of coverage.
\end{abstract}

JEL-Classification: D82, G22, I11

Keywords: Supplemental Health Insurance; Adverse Selection; Insurance Demand; German Statutory Health Insurance; Insurance Affinity

\footnotetext{
a Institute for Health Care \& Public Management, University of Hohenheim, Stuttgart, Germany.

${ }^{\text {b } C o r r e s p o n d i n g ~ a u t h o r, ~ j . s c h i l l e r @ u n i-h o h e n h e i m . d e, ~ p h o n e: ~+49 ~} 711$ 22863, fax: +49 71145923953.

' School of Risk Management, Insurance and Actuarial Science, St. John's University New York, NY, USA.
} 


\section{Introduction}

As a consequence of high and steadily increasing health care costs, there is a common trend in countries with public health care systems toward incrementally reducing benefits. The decision to complement public coverage is left to individuals depending on their financial ability, preferences, and farsightedness with respect to future health risks. Particularly, supplemental health insurance (Sup$\mathrm{pHI}$ ) is highly relevant in regulated health care systems with standardized statutory coverage and restricted choice of health-care providers and services, as e.g., in Germany, France, Belgium and the Netherlands (Saliba and Ventelou, 2007; Van de Ven and Schut, 2008; Schokkaert et al., 2010; Simon, 2013). In the U.S. as well, there is a significant market for SuppHI added on to the social health insurance for the elderly, i.e., Medicare (McCall et al., 1986; Garfinkel et al., 1987; Pourat et al., 2000; Goldman and Zissimopoulos, 2003).

In Germany, 17.55 million supplemental coverage policies were in place in 2012 among the 69.71 million individuals who were insured under public coverage. Approximately 5.8 million Germans had hospital SuppHI, and 13.6 million had dental coverage (Financial Report for Private Healthcare Insurance, 2012). Premiums that were written along these lines accounted for $19.73 \%$ of the overall private market for health and long-term care insurance. Because underwriting by insurers in German SuppHI is rather limited, these markets are prone to asymmetric information, which could result in adverse selection. Given the significance of SuppHI, we aim to find the main determinants of demand and investigate whether the market suffers from adverse selection using the German SocioEconomic Panel (SOEP).

We particularly focus on two types of SuppHI, namely, hospital benefits and supplemental dental insurance, for the following reasons: First, these types of SuppHI constitute the two lines of business with the highest demand in the German market. Second, motives for the purchase of supplemental coverage may differ. Supplemental hospital insurance mainly focuses on quality aspects and enhances the publicly provided insurance, whereas supplemental dental coverage focuses in particular on protecting against the financial risks that arise from coverage gaps in SHI benefits. Part of our contribution is to compare a quality- and financially oriented line of SuppHI and to discuss the similarities and differences in one paper.

When analyzing the demand for any type of insurance or different levels of insurance coverage in a competitively structured market, asymmetric information (adverse selection and/or moral hazard) might lead to inefficient outcomes. A widespread approach to testing for asymmetric information is to examine the correlations between the chosen insurance contracts and the occurrence or 
severity of losses (Abbring et al., 2003). ${ }^{1}$ From an empirical point of view, it is difficult to disentangle adverse selection (higher risks choose more generous coverage) from moral hazard (more extensive coverage may increase health expenditures) because the causal relationship between cost and coverage can be reversed (Chiappori and Salanié, 2000; Vargas and Elhewaihi, 2008; Gardiol et al., 2011). Many studies overcome the problem of unobserved preferences and moral hazard by simultaneously estimating the demand for and utilization of health services (Holly et al., 1998; VeraHernández, 1999; Schellhorn, 2001; Nuscheler and Knaus, 2005; Werblow and Felder, 2003; Schokkaert et al., 2010). Other studies use the individuals' self-assessed health status to test for adverse selection (Browne, 1992; Christoph, 2003). However, the latter approach is controversial because of measurement error, and its reliability is strongly related to other observable variables such as age, income, and occupation (Crossley and Kennedy, 2002; Kapfer, 2008).

In our analysis, the issue of disentangling adverse selection from moral hazard and the shortcomings of individuals' self-assessed health status is not very serious inasmuch as the recent expansion of the SOEP in 2009 includes data on chronic diseases that were diagnosed by a doctor. Linking the doctors' diagnoses with the socioeconomic information from the previous year, we are able to comprehensively assess the individuals' risk type and to control for a variety of factors that are suspected to impact insurance demand and possibly overshadow adverse selection effects, such as risk attitude, income, and insurance affinity (Finkelstein and McGarry, 2006).

Adverse selection has been discussed repeatedly in the economics literature (Pauly, 1974; Rothschild and Stiglitz, 1976; Wilson, 1977), but depending on the line of coverage and the dataset, evidence of adverse selection has been mixed. ${ }^{2}$ This is also the case with SuppHI. Marquis and Phelps (1987) investigated the potential impact of adverse selection issues on the demand for SuppHI in the RAND health experiment and found health characteristics to be an important driver of insurance demand. A number of studies find mild evidence of adverse selection in the Medicare SuppHI market (Medigap) (Woolfe and Goddeeris, 1991; Browne and Doerpinghaus, 1994; Ettner, 1997). Using SOEP data to analyze the German SuppHI market, Christoph (2003) and Kapfer (2008) find evidence of risk selection, and Schmitz (2011) identifies advantageous selection. Bauer et al. (2015) do not find selection effects when analyzing the overall German supplemental dental insurance market, but they do identify a subgroup of advantageous selectors. For other European health insurance systems, there is

\footnotetext{
${ }^{1}$ In the health insurance context, medical expenditure data and other medical consumption data, i.e., number of hospital stays or nights, is often used to approximate the occurrence or severity of a loss.

${ }^{2}$ In car insurance, the majority of studies have not found evidence of adverse selection (e.g., Chiappori and Salanié, 2000; Kim et al., 2009; Dionne et al., 2001; Zavadil, 2011). Finkelstein and Poterba (2004) find evidence of adverse selection with respect to the choice of different types of annuity insurance policies but not with respect to annuity size. Cohen and Siegelman (2010) provide a comprehensive survey on empirical findings of adverse selection in insurance.
} 
only weak evidence for adverse selection (Schokkaert et al., 2010), and its impact on the demand for SuppHI is negligible (Saliba and Ventelou, 2007; Shmueli, 2010).

In contrast to previous studies, we divide our dataset into two age groups: individuals age 65 and younger and individuals above age 65. Different preferences among these age groups may offer one possible explanation for the mixed findings with respect to adverse selection in previous studies. We find evidence for adverse selection among individuals aged 65 and younger: less healthy individuals are more likely to buy hospital SuppHI. For seniors, we see the reverse effect, namely, that healthier individuals are more likely to hold hospital SuppHI. We attribute this to a decline in private information on health status over one's lifetime as argued by Peter et al. (2014). In the two investigated lines of SuppHI, we find that insurance affinity, measured by switching behavior in statutory health insurance (SHI) and the demand for life insurance, positively affects the demand for SuppHI. Finally, income positively affects the demand for both types of SuppHI.

The remainder of this paper is structured as follows. In Section 2, we give a short overview of the institutional background and the role of SuppHI in Germany. Section 3 presents our hypotheses. A description of the data and methodology follows in Section 4. We then present and discuss the results from our empirical analysis (Section 5) and validate the robustness of our results in Section 6. The final section concludes the paper.

\section{Institutional Background and Supplemental Health Insurance in Germany}

Nearly $90 \%$ of the German population is insured under the public SHI, with highly uniform and regulated coverage. Nonprofit sickness funds provide coverage, and SHI participants can freely choose their sickness fund. Premiums are income-related, with average contribution rates of approximately $14 \%$ of gross income for $2008 .^{3}$ Only $10 \%$ of the German population is insured under private health insurance (PHI) given that individuals only become eligible for private insurance if their income is above a threshold ( $€ 48,150$ in 2008 ) or they are either self-employed or civil servants. For eligible individuals, there is the choice to opt out of SHI to obtain private coverage or to remain under SHI. $\mathrm{PHI}$ coverage is less strictly regulated and subject to individual underwriting with risk-based premiums, and therefore, it is especially attractive to healthy and high-income individuals.

Over the last two decades, a number of cost-control policies that restrict SHI coverage have resulted in increased out-of-pocket expenses (e.g., the 2004 health care reform significantly cut benefits for dental care and increased co-payments for prescribed drugs). This contributed to the rising demand for SuppHI in Germany. Based on data from the SOEP, Figure 1 illustrates the demand for

\footnotetext{
${ }^{3}$ Until 2008, SHI funds charged different contribution rates depending on their risk structure and profitability.
} 
SuppHI of insured under SHI in percent overall and by line of business between 1999 and $2008 .{ }^{4}$ In 1999 , only $8.24 \%$ of individuals who were insured under SHI had SuppHI, whereas by 2008, approximately $22.68 \%$ held additional health insurance coverage. SuppHI for hospital benefits rose rather constantly over time as measured by the portion of publicly insured. The demand for the other three lines of business rose substantially. This was especially the case for supplemental dental insurance after the health reform of 2004, which increased by $231 \%$ between 2004 and 2008 (from $7.39 \%$ to $17.07 \%)$.

Figure 1: Share of SHI members with SuppHI (overall and by line of business), 1999-2008

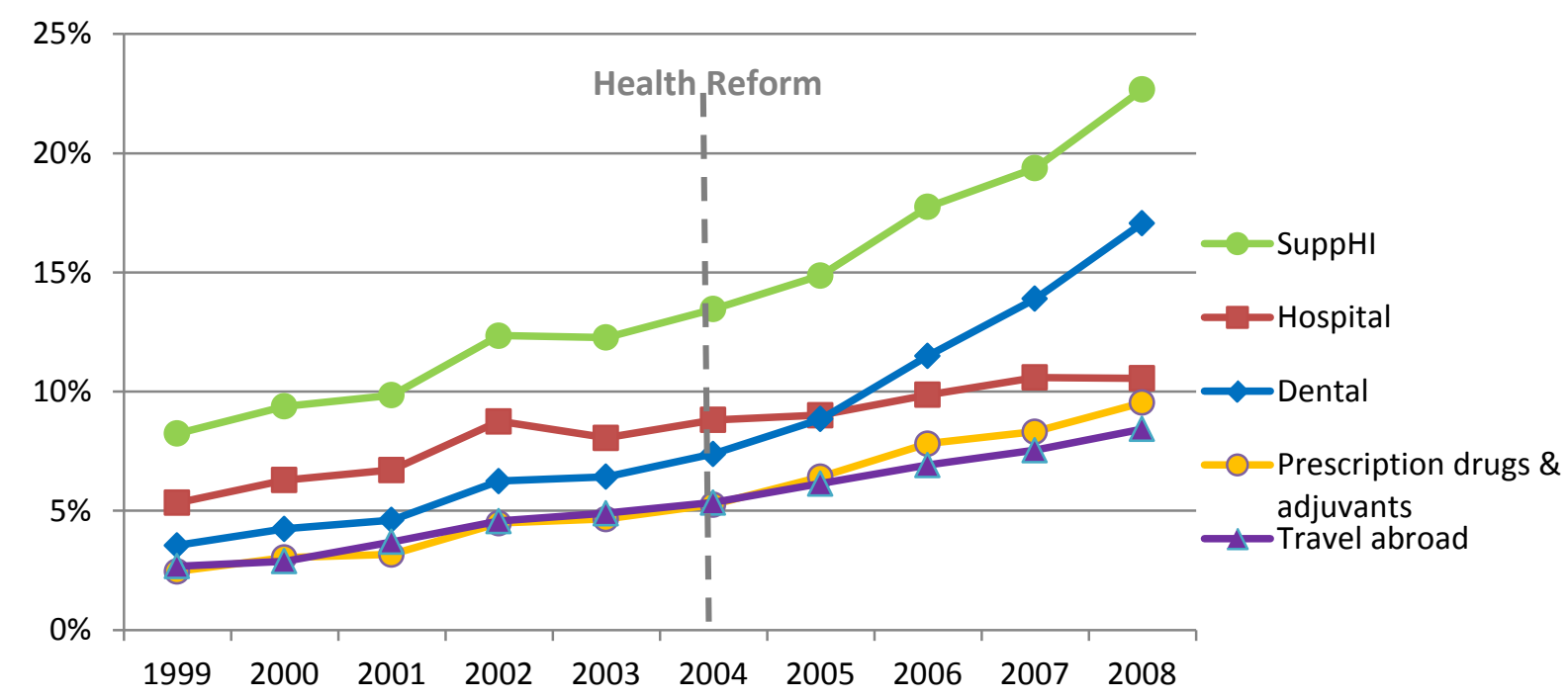

SuppHI contracts are sold by the private insurance industry. There are four major types: hospital benefits, dental benefits, prescription drugs and adjuvants, and health insurance when travelling abroad. Supplemental hospital benefits cover semi-private or private rooms rather than public wards and treatments by more senior physicians (e.g., the chief physician). SuppHI mostly aims at improving the quality of care during hospitalization. Dental coverage predominantly closes the coverage gap in SHI benefits and also includes higher-quality services such as better fillings, etc. Thus, SuppHI can be regarded as a hybrid between pursuing quality and reducing out-of-pocket expenses. The main purpose of prescription and adjuvant plans is to reduce out-of-pocket expenses, whereas SuppHI when travelling abroad covers costs of treatments and return transport from overseas (outside of the European Union). The Association of German Private Healthcare Insurers reported in its annual financial statement an amount of 20.98 million SuppHI policies in place in 2008. Nearly three-

\footnotetext{
${ }^{4}$ Differences in the percentages of SHI insured who hold SuppHI, from SOEP data and the Association of Private Healthcare Insurers, arise from the fact that individuals under age 17 years are not included in the SOEP.

${ }^{5}$ Figure 1 is based on SOEP data from 1999-2008 (SOEP v25). The percentage of SuppHI is not the sum of the percentages in the different lines of business because individuals can hold multiple supplemental health benefits under SuppHI insurance.
} 
quarters, $73.36 \%$, were bought by insured under SHI. This equals a proportion of $21.92 \%$ of those who are insured under $\mathrm{SHI}^{6}$ holding additional private health insurance coverage (Association of German Private Healthcare Insurers, 2010).

SuppHI contracts are underwritten on an individual basis and are guaranteed renewable (Pauly et al., 1995). Individual underwriting is most rigorous for hospital benefits using the same standards as private comprehensive health plans. The underwriting for supplemental hospital coverage includes questions on gender, age, height, weight, occupation, and whether the individual is insured under SHI or PHI. Additionally, applicants must report information on any hospital stay, psychotherapy, or medication within the last five years. Premiums in the market are therefore riskbased, and insurance companies can deny applicants based on preexisting health conditions. Dental SuppHI also utilizes risk-based underwriting, but in less detail.

\section{Hypotheses}

We investigate three different hypotheses in our paper with respect to adverse selection, insurance affinity, and income. In this section, we first briefly outline the theoretical foundation for our detailed hypotheses before we state them. The section also provides a discussion of the control variables that we employ based on the existing literature.

Adverse selection: Adverse selection is one of the most commonly discussed insurance market imperfections and may lead to an inefficient market outcome because low-risk policyholders may be rationed (Rothschild and Stiglitz, 1976). We restrict our analysis of adverse selection to hospital SuppHI because there are no dental health indicators in the SOEP data. Adverse selection models à la Rothschild and Stiglitz (1976) suggest that individuals with poorer health are more interested in purchasing supplemental hospital benefits as well as renewing their existing plans because they are more likely to consume medical services. At the same time, insurance companies underwrite risks individually in the attempt to overcome potential issues of adverse selection (Shmueli, 2010).

An individual's health status can impact the demand for SuppHI in two ways according to the theory of adverse selection: Individuals with chronic diseases may be expected to more likely initiate obtaining coverage and to renew their policies (Cohen and Siegelman, 2010), which are guaranteed renewable in Germany. Our dataset allows us to draw conclusions about the aggregate effect as we compare health states between individuals who do and do not have hospital SuppHI. ${ }^{7}$

A number of arguments can be considered that could potentially explain the mixed evidence on the existence of adverse selection in SuppHI that was discussed in the introduction. One reason is

\footnotetext{
${ }^{6}$ Calculations are based on actual SHI insurance status numbers from the German Ministry of Health (2009), $p$ 65.

${ }^{7}$ Note that the dataset does not provide detailed information to disentangle these two potential adverse selection sources.
} 
the varying underwriting standards and contract characteristics in different countries, which naturally influence the existence and magnitude of potential adverse selection issues. Other arguments relate to measurement errors: Self-reported health status is often critiqued for including multiple biases given that actual health is more continuous than discrete. Furthermore, individuals vary in their perceptions, or they may have different reference points when they are asked to judge their health (Kapfer, 2008).

Following Bolhaar et al. (2012), we use an indicator variable to estimate the individual's health status using doctor-diagnosed ailments: asthma, cancer, coronary heart disease (CHD), dementia, depression, diabetes, high blood pressure, and migraines. Supposedly, we have comparable information on individuals' risk type as German private insurers gain from medical underwriting with respect to sickness information and previous hospital stays. A simple t-test shows that the likelihoods of hospital stays and number of hospital nights are statistically significantly greater at the $1 \%$ level for individuals with one of the abovementioned diseases or ailments. This implies that individuals with one or more of these diagnoses can be expected to cause higher expected hospital costs. At the same time, we do not expect a significant moral hazard problem with respect to hospital SuppHI because these diseases are generally diagnosed by primary care doctors. Furthermore, the reliability of our health variable compared with self-reported measures is unlikely to have been affected by, e.g., socioeconomic status because all observed individuals are insured under German SHI. ${ }^{8}$

In our analysis, we test whether the observed health status in 2009 measured by doctordiagnosed illnesses has an impact on holding SuppHI in 2008. ${ }^{9}$ Given the chronic nature of most of the included diseases in our sample, it is likely that a significant number of the individuals who were identified as chronically ill in 2009 were already sick in 2008, and the sick variable is also likely to capture individuals with private information on their future health status, i.e., those who could come down with one of these illnesses in the following year.

Medical service utilization could also be vulnerable to bias due to moral hazard. Accordingly, we do not construct a bivariate model in order to test for adverse selection using individuals' numbers of hospital stays, days hospitalized, or doctor visits but instead utilize our constructed indicator variable. This circumvents the problem of having to disentangle adverse selection effects from (ex post) moral hazard (Dardanoni and Li Donni, 2012). Kapfer (2008) uses a bivariate adverse selection model and does not find evidence for adverse selection in the German market for SuppHI. Furthermore, Cohen (2005) argues that differing findings of the cost-coverage relationship among different subgroups in the sample imply hidden information rather than hidden action. This supports our ad-

\footnotetext{
${ }^{8}$ Crossley and Kennedy (2002) find that the reliability of self-assessed health status is strongly related to other observable variables such as age, income, and occupation.

${ }^{9}$ We merge the 2009 sickness data into the 2008 dataset because doctor-diagnosed diseases were not surveyed in 2008 and information on supplemental health insurance is not available in the 2009 data.
} 
verse selection hypothesis as we find different results regarding adverse selection based on age group.

Furthermore, adverse selection effects may be overshadowed by individual preferences that imply advantageous selection (Finkelstein and Mc Garry, 2006). We are able to control for a range of individual preferences that have been suspected to potentially cause advantageous selection such as risk attitude, financial situation, and the propensity to purchase insurance (Cohen and Siegelman, 2010).

One of our main contributions to the discussion of adverse selection in SuppHI is that we distinguish age-specific effects. That is, we investigate whether different age groups may be impacted to varying degrees by adverse selection. Peter et al. (2014) argue that private information on health status resolves as most illnesses materialize over time, i.e., towards retirement age and older. Fang et al. (2008) even find evidence that retired individuals in the U.S. with SuppHI (Medigap) to complement Medicare have significantly lower health expenditures than do individuals without SuppHI. Accordingly, we separately investigate retired and non-retired individuals and also control for age groups specifically.

In sum, we propose the adverse selection hypothesis as follows:

Hypothesis 1: Supplemental hospital insurance suffers from adverse selection for non-retired individuals.

Affinity to insurance: A number of studies show that some individuals have a higher propensity to insure than others after demographic and socioeconomic factors are controlled for (Pourat et al., 2000; Saliba and Ventelou, 2007; Schokkaert et al., 2010)). We use the person's observed effective demand for life insurance and whether an individual has switched her SHI in the previous year to create two dichotomous variables that we characterize as "insurance affinity." Both measures indicate whether an individual has acquainted herself with the concept of insurance and will therefore be considered to have an insurance affinity. The variable Change of SHI provider indicates whether an individual has switched to another SHI fund in the previous period. Changing the SHI fund involves decisions concerning insurance, financial, and quality aspects and therefore implies that the insured person consciously made a decision for a specific sickness fund. Previous studies that used SOEP data (Christoph, 2003; Kapfer, 2008) find a positive impact of whether an individual has switched his sickness fund in the last year on the likelihood of holding supplemental health insurance, but holding life insurance has not been included in their analyses; we, however, add this to our analysis. 
In this context, we further include the individuals' self-assessed risk attitude to disentangle insurance affinity from varying risk attitudes among individuals. ${ }^{10}$ Theoretically, it is assumed that the individual's demand for insurance increases with the degree of risk aversion. Hence, a more riskaverse individual is more likely to purchase insurance and to spend more on insurance (Dionne and Eeckhoudt, 1985; Briys and Schlesinger, 1990). In order to control for changes in individual risk attitudes caused by changes in wealth, we control for the interaction of risk attitude and adjusted household income in our regressions.

Thus, we propose the insurance affinity hypothesis as follows:

Hypothesis 2: Insurance affinity increases the demand for SuppHI.

Income: A number of studies have also investigated the impact of income on the demand for SuppHI in different countries. Garfinkel et al. (1987) investigate the demand for SuppHI under Medigap in the U.S. and find that higher-income individuals are more likely to have insurance coverage. Borrell et al. (2001) investigate the demand for SuppHI coverage in Spain, which offers a higher quality of care (reduced wait times and elective surgeries), and they find that higher social class is an indicator. A study by Schokkaert et al. (2010) on Belgian SuppHI indicates a strong impact of socioeconomic background, and Saliba and Ventelou (2007) also find a strong and significant effect of income on the decision to purchase SuppHI in France. Vargas and Elhewaihi (2008) investigate SOEP data and find that a higher income is positively correlated with having SuppHI in Germany. Their cross-sectional probit model, however, indicates that income is only significant at the $10 \%$ level, and they do not account for the different types of SuppHI that vary from health insurance for travel, which costs a small number of Euro per year, to hospital SuppHI, which can amount to $€ 50-70$ per month. Accordingly, motives for seeking the different types of coverage can be suspected to vary widely. In our analysis, we use the logarithmic adjusted household income definition from the SOEP dataset. We later test the robustness of results by using per capita income.

Our study provides insights from the demand for SuppHI for lines that are more quality oriented as well as aiming at closing coverage gaps in the same country. This is particularly interesting given that we assume that income should have a differing impact on these lines. We hypothesize that income generally has a positive impact on the demand for SuppHI because sufficient funds must be available in order to afford SuppHI. At the same time, more income also enables the individual to cover possible out-of pocket expenses more easily given his or her ongoing financial situation. Ac-

\footnotetext{
${ }^{10}$ Dohmen et al. (2011) shows that the self-reported risk attitude in the SOEP is a surprisingly reliable indicator of an individual's risk preferences.
} 
cordingly, we hypothesize that the income effect should be lower for dental SuppHI than for hospital SuppHI because the first one is more affordable and mostly aims at closing coverage gaps.

Although dental procedure expenses can easily reach high levels (particularly when considering a top-quality complete dental replacements), dental SuppHI covers the gap in SHI benefits for reasonable insurance premiums that are affordable to the majority of the German population.

Supplemental hospital insurance mostly aims at improving the quality of hospital services that are offered to the individual. Because this coverage is significantly more expensive, we believe that income is even more important in this line of insurance. Better-quality care is often believed to imply a quicker recovery, and this particularly pays off for higher-income individuals because they receive less or no income replacement for prolonged illnesses, which should make hospital SuppHI even more attractive to this group. The following hypothesis summarizes the discussion:

Hypothesis 3: Higher income increases the demand for SuppHI. We see a stronger impact of income for hospital insurance than for dental coverage.

In addition to our three main hypotheses, we also control for a number of characteristics that have been repeatedly discussed in the literature. The likelihood of demand for SuppHI is related to numerous demographic factors such as gender (Schokkaert et al., 2010), age (Browne and Doerpinghaus, 1994), household size (Ettner, 1997), education (Dardanoni and Li Donni, 2012), occupational status and regional differences (Saliba and Ventolou, 2007). In addition, we include data on the type of SHI (Kapfer, 2008), and we control for appropriate weight using the body-mass-index (BMI) (Schokkaert et al., 2010). Furthermore, our dataset includes information on self-reported risk attitude, which we also incorporate in our model. We use this variable in our analysis rather than proxy variables for risk attitude such as smoking because Dohmen et al. (2011) demonstrated the validity of the self-reported measure. This variable is of particular relevance to the study of adverse selection because individual preferences can overshadow adverse selection effects, as discussed by Finkelstein and McGarry (2006). Often, researchers do not have information on risk attitude available, particularly if they use data from an insurance company, as did Browne (1992). 


\section{Data and Methodology}

In our analysis, we use data from the SOEP, which is a representative, longitudinal panel survey of private households in Germany that contains around 12,000 households with approximately 21,000 individuals. ${ }^{11}$ The survey has been conducted on a yearly basis since 1984. In addition to demographic and socioeconomic variables, the dataset includes various health indicators, data on life satisfaction, and information on health insurance (Wagner et al., 2007).

Individuals who are insured under German SHI are asked whether they have additional private health insurance and which benefits are covered, e.g., hospital, dental and/or other additional coverage. This constitutes our two binary coded dependent variables, indicating whether an individual holds hospital or dental SuppHI or not.

For our analysis, we use the 2008 wave of the SOEP. It contains the most recent available data on SuppHI, which we can merge with information on doctor-diagnosed illnesses in the following year. ${ }^{12}$ The complete sample covers 19,664 observations. We drop individuals who report being either civil servants or self-employed because these individuals mostly insure themselves under private health insurance. Furthermore, we clean the data of individuals who unofficially work within the family because their health insurance status is unclear. In addition, we drop 1,486 individuals who report not being covered under SHI. We lose another 1,437 individuals when we merge the 2009 sickness data into the 2008 dataset. As a last step, we clean the data of missing values for the controls. We then divide the dataset into two subsets, the first subset with individuals age 65 and younger (9,804 observations) and the second containing individuals older than 65 (3,030 observations). We do this for the following reasons: As explained above, we hypothesize that private information on health status diminishes with age. In addition, we measure insurance affinity with a variable for whether an individual holds life insurance. Because there are rigid age limits in the German market for life insurance that exclude the majority of seniors from initiating or continuing coverage, we suspect that holding life insurance will not be a powerful predictor of insurance affinity for seniors.

\footnotetext{
${ }^{11}$ Households answer a household questionnaire. All household members then answer an individual questionnaire. The dataset maps individuals to their households. Individuals are allowed to participate from the age of 17 years.

${ }^{12}$ Note that the SOEP data are published with substantial delay.
} 
Figure 2: Number of individuals and percentages of hospital and dental supplemental health insurance and sick in 2009 in the different age intervals $(n=12,834), 2008^{13}$

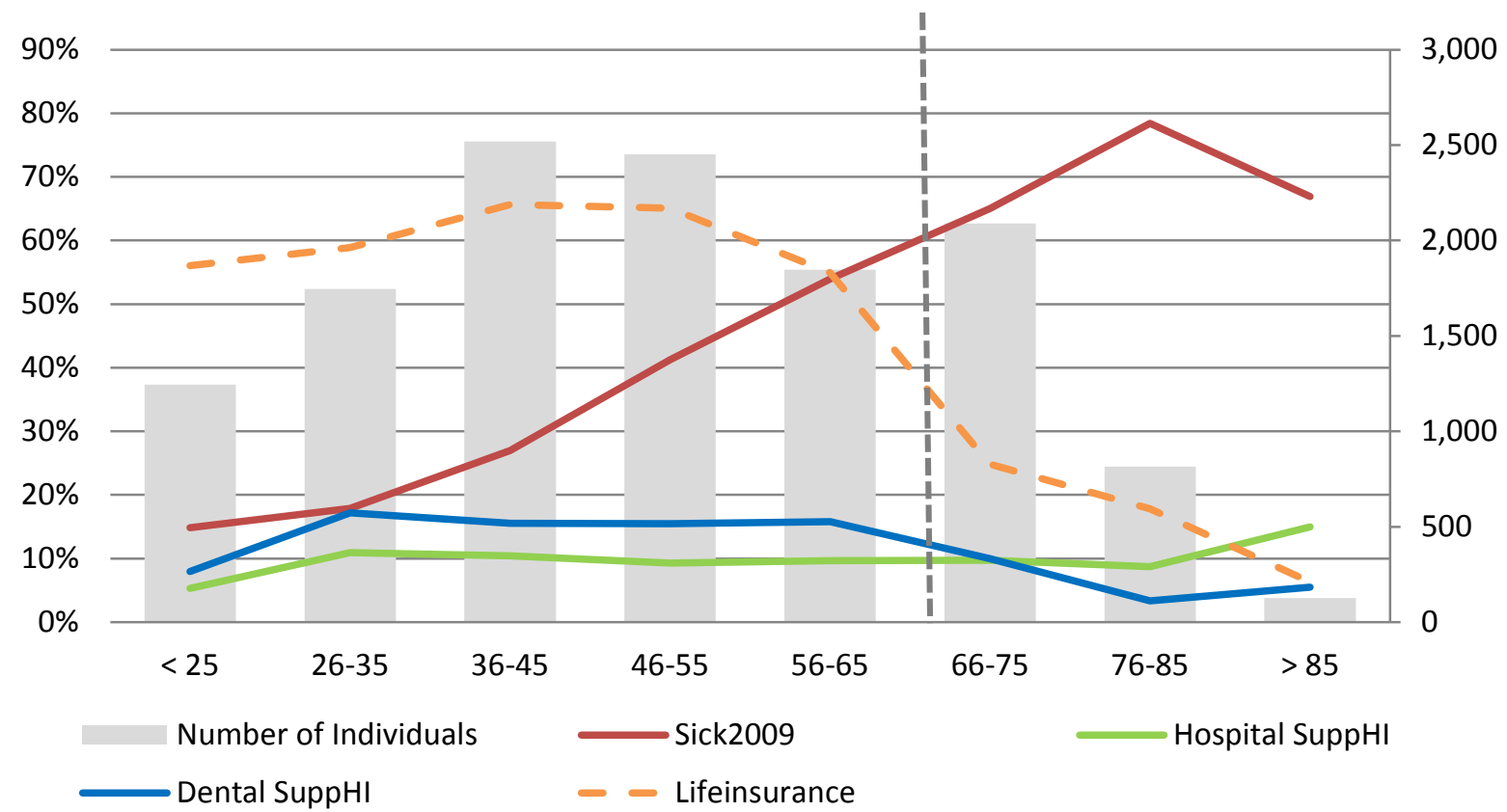

The exogenous regressors contain a set of control variables such as gender, age, income, occupational status and group, education, household size, and state of residence. Insurance status differs with regard to whether the insured is a compulsory or a voluntarily member, family insured (i.e., nonworking spouse or child) or other member (i.e., unemployed or retiree) of the SHI. We also control for whether an individual has switched her SHI fund in the previous period, which indicates an individual's willingness to put effort into designing his or her health insurance.

In 2009, questions on chronic diseases diagnosed by a doctor were included in the SOEP for the first time; therefore, we merge the 2009 sickness data into our 2008 dataset. Because of the chronic nature of these diseases, it is straightforward to assume that nearly all individuals who reported one of the diseases in $\mathbf{2 0 0 9}$ had already been at least partially affected in the previous wave and therefore had information that would influence their demand for SuppHI.

We create a sickness indicator variable that equals 1 if an individual has one or more of the following diseases: asthma, cancer, coronary heart disease, diabetes, hypertension, migraines, dementia or depression. Table 1 displays the means of these chronic conditions in our sample. Overall, $32.47 \%$ of the individuals (younger 65 years) in our sample are sick according to our indicator variable. $^{14}$

\footnotetext{
${ }^{13}$ The percentage numbers of hospital and dental supplemental health insurance and sick in 2009 correspond to the left $\mathrm{Y}$-axis. The number of individuals in the different age intervals corresponds to the right $\mathrm{Y}$-axis.

${ }^{14}$ The variable Sick in 2009 also contains individuals who were affected by more than one disease; thus, 32.47\% is not the sum of the means of the different chronic diseases.
} 
Table 1: Summary statistics of chronic diseases diagnosed by a doctor in $2009^{15}$

\begin{tabular}{l|cc|cc|cc}
\hline & \multicolumn{2}{|c|}{ Individuals age $\leq 65$} & \multicolumn{2}{c|}{ Individuals age $>65$} & \multicolumn{2}{c}{ Individuals age 18-99 } \\
\hline Variable & Observations & Mean & Observations & Mean & Observations & Mean \\
\hline Diabetes & 9,804 & 0.0424 & 3,030 & 0.1894 & 12,834 & 0.0771 \\
Asthma & 9,804 & 0.0473 & 3,030 & 0.0587 & 12,834 & 0.0500 \\
CHD & 9,804 & 0.0417 & 3,030 & 0.2627 & 12,834 & 0.0939 \\
Cancer & 9,804 & 0.0248 & 3,030 & 0.0884 & 12,834 & 0.0398 \\
Migraines & 9,804 & 0.0576 & 3,030 & 0.0320 & 12,834 & 0.0516 \\
Hypertension & 9,804 & 0.1752 & 3,030 & 0.4719 & 12,834 & 0.2453 \\
Dementia & 9,804 & 0.0004 & 3,030 & 0.0099 & 12,834 & 0.0497 \\
Depression & 9,804 & 0.0534 & 3,030 & 0.0376 & 12,834 & 0.0026 \\
\hline Sick in 2009 & 9,804 & 0.3247 & 3,030 & 0.6868 & 12,834 & 0.4102 \\
\hline
\end{tabular}

Table 2 displays the correlation between the different diseases, including significance levels. Depression is statistically significantly correlated with all other diseases. Furthermore, hypertension has significant correlations with diabetes, coronary heart disease, cancer, dementia and depression. The highest correlation coefficients are between hypertension and diabetes and between hypertension and coronary heart disease.

Table 2: Correlation matrix of comorbidities

\begin{tabular}{l|l|l|l|l|l|l|l|l}
\hline & Diabetes & Asthma & CHD & Cancer & Migraines & $\begin{array}{l}\text { Hyper- } \\
\text { tension }\end{array}$ & Dementia & Depression \\
\hline Diabetes & 1 & & & & & & & \\
\hline Asthma & 0.0079 & 1 & & & & & & \\
\hline CHD & $0.1636^{* * *}$ & 0.0112 & 1 & & & & & \\
\hline Cancer & $0.0218^{* *}$ & 0.0046 & $0.0324^{* * *}$ & 1 & & & & \\
\hline Migraines & 0.0001 & $0.0603^{* * *}$ & 0.0119 & 0.0028 & 1 & & & \\
\hline Hypertension & $0.2411^{* * *}$ & 0.0148 & $0.2004^{* * *}$ & $0.037^{* * *}$ & $0.0219^{* *}$ & 1 & & \\
\hline Dementia & -0.0043 & $0.0193^{*}$ & -0.0042 & -0.0032 & -0.005 & $0.0173^{*}$ & 1 & \\
\hline Depression & $0.0715^{* * *}$ & $0.0624^{* * *}$ & $0.0797^{* * *}$ & $0.038^{* * * *}$ & $0.093^{*}$ & $0.0766^{* * *}$ & $0.0177^{*}$ & 1 \\
\hline
\end{tabular}

Correlation coefficients reported. $* * *, * *, *$ significance at the $1 \%, 5 \%$ and $10 \%$ levels, respectively.

Previous studies on the demand for SuppHI and adverse selection in health insurance had to rely on self-reported health status measures or on data from the SF-12 questionnaire, which generates a quality of life measure that includes questions on physical and emotional well-being, energy

\footnotetext{
${ }^{15}$ Table 1 is based on SOEP data from 2009. The percentages above are very similar to the stated percentages concerning the sickness structure of the Belgian population in Schokkaert et al. (2010).
} 
and fatigue and is frequently used in studies that include health status. ${ }^{16}$ Following an approach that is similar to that of Schokkaert et al. (2010) for Belgian data, we use the SOEP data including actual sickness indicators. Using these indicators, we are able to find evidence for adverse selection.

The descriptive statistics of our sample, which consists of 9,804 observations, show that 925 individuals (9.43\%) held supplemental hospital insurance in 2008 (Table 3). Even accounting for individual underwriting and insurers' potentially denying coverage because of preexisting conditions, 307 of the individuals with hospital SuppHI are defined as sick according to our indicator variable.

Table 3: Number of chronically ill and number of supplemental hospital contracts in 2008

\begin{tabular}{llll}
\hline & Hospital SuppHI & No Hospital SuppHI & Total \\
\hline Sick in 2009 & 307 & 2,876 & 3,183 \\
Not Sick in 2009 & 618 & 6,003 & 6,621 \\
\hline Total & 925 & 8,879 & 9,804 \\
\hline
\end{tabular}

In addition to demographic and socioeconomic variables (e.g., education, occupational status, and logarithmic adjusted household income), and data on health insurance status (i.e., compulsory, voluntary, family or other insured), we consider individual factors, e.g., individual health and insurance affinity, as exogenous regressors in our model as explained in the previous section. To estimate the demand decision for supplemental hospital and dental coverage, we fit two independent probit equations for the dichotomous event of purchasing versus not purchasing supplemental hospital and dental coverage with respect to socioeconomic, demographic, and individual factors, assessing, e.g., their health and risk type, insurance affinity, and health. A general formulation of this model is:

$$
\begin{aligned}
& P(\text { Hospital SuppHI })=\alpha+\beta \cdot X_{i j}+\varepsilon_{i j} \text { with } i=1, \ldots, N \text { and } j=1, \ldots, M \\
& P(\text { Dental SuppHI })=\alpha+\beta \cdot X_{i j}+\varepsilon_{i j} \text { with } i=1, \ldots, N \text { and } j=1, \ldots, M
\end{aligned}
$$

where $\mathrm{N}=$ sample size and $\mathrm{M}=\#$ of variables.

Furthermore, we run the Cohen-Siegelman test for adverse selection where we regress the existence of coverage on risk type including all relevant controls. Accordingly, we have the following equation:

$$
P\left(\text { Sick2009) }=\theta+\vartheta \cdot \text { HospSuppHI }+\mu \cdot Y_{i j}+\gamma_{i j} \text { with } i=1, \ldots, N \text { and } j=1, \ldots, M\right.
$$

Table 4 illustrates the summary statistics for all variables included in the full sample and the subsamples.

\footnotetext{
${ }^{16}$ The SF-12 surveys 12 health and well-being questions and creates an index of an individual's well-being (Kapfer, 2008; Vargas and Elhewaihi, 2008; Schmitz, 2011; Browne, 1992).
} 
Table 4: Summary statistics of variables in the full sample and subsamples, 2008 (SOEP v25)

\begin{tabular}{|c|c|c|c|c|c|c|c|c|c|}
\hline \multirow[b]{2}{*}{ Variables } & \multicolumn{3}{|c|}{ Individuals age 18-99 } & \multicolumn{3}{|c|}{ Individuals age $\leq 65$} & \multicolumn{3}{|c|}{ Individuals age $>65$} \\
\hline & Obs. & Mean & $\sigma$ & Obs. & Mean & $\sigma$ & Obs. & Mean & $\sigma$ \\
\hline \multicolumn{10}{|l|}{ Dependent variables } \\
\hline Hospital benefits & 12,834 & 0.09 & 0.29 & 9,804 & 0.09 & 0.29 & 3,030 & 0.1 & 0.3 \\
\hline Dental benefits & 12,834 & 0.13 & 0.34 & 9,804 & 0.15 & 0.36 & 3,030 & 0.08 & 0.27 \\
\hline \multicolumn{10}{|l|}{ Variables of interest } \\
\hline Household income (log) & 12,834 & 7.77 & 0.55 & 9,804 & 7.84 & 0.55 & 3,030 & 7.54 & 0.49 \\
\hline Sick in 2009 & 12,834 & 0.41 & 0.49 & 9,804 & 0.32 & 0.47 & 3,030 & 0.69 & 0.46 \\
\hline Life insurance & 12,834 & 0.52 & 0.50 & 9,804 & 0.61 & 0.49 & 3,030 & 0.22 & 0.42 \\
\hline Change of SHI provider & 12,834 & 0.05 & 0.22 & 9,804 & 0.06 & 0.25 & 3,030 & 0.02 & 0.12 \\
\hline \multicolumn{10}{|l|}{ Control Variables } \\
\hline Male & 12,834 & 0.45 & 0.50 & 9,804 & 0.45 & 0.5 & 3,030 & 0.45 & 0.5 \\
\hline Age & 12,834 & 49.80 & 17.49 & 9,804 & 42.54 & 12.88 & 3,030 & 73.31 & 6 \\
\hline Age: younger than 25 & 12,834 & 0.10 & 0.30 & 9,804 & 0.13 & 0.33 & & & \\
\hline Age: 26-35 & 12,834 & 0.14 & 0.34 & 9,804 & 0.18 & 0.38 & & & \\
\hline Age: $36-45$ & 12,834 & 0.20 & 0.40 & 9,804 & 0.26 & 0.44 & & & \\
\hline Age: 4 & 12,834 & 0.19 & 0.39 & 9,804 & 0.25 & 0.43 & & & \\
\hline Age: 56-65 & 12,834 & 0.14 & 0.35 & 9,804 & 0.19 & 0.39 & & & \\
\hline Age: $66-75$ & 12,834 & 0.16 & 0.37 & & & & 3,030 & 0.69 & 0.46 \\
\hline Age: 76-85 & 12,834 & 0.06 & 0.24 & & & & 3,030 & 0.27 & 0.44 \\
\hline Age: Older than 85 & 12,834 & 0.01 & 0.10 & & & & 3,030 & 0.04 & 0.2 \\
\hline BMI & 12,834 & 26.20 & 4.66 & 9,804 & 25.89 & 4.77 & 3,030 & 27.18 & 4.16 \\
\hline Househo & 12,834 & 2.61 & 1.23 & 9,804 & 2.86 & 1.26 & 3,030 & 1.8 & 0.61 \\
\hline Monthly net in & 12,834 & 2,746 & 1,613 & 9,804 & 2,935 & 1,662 & 3,030 & 2,138 & 1,265 \\
\hline Risk attitude & 12,834 & 4.35 & 2.28 & 9,804 & 4.52 & 2.24 & 3,030 & 3.8 & 2.32 \\
\hline Hospital stay ir & 12,834 & 0.11 & 0.32 & 9,804 & & 0.29 & & 0.18 & 0.39 \\
\hline Self-ass. he & 12,834 & 0.08 & 0.27 & 9,804 & 0.1 & 0.3 & 3,030 & 0.02 & 0.13 \\
\hline Self-ass. health: Good & 12,834 & 0.39 & 0.49 & 9,804 & 0.45 & 0.5 & 3,030 & 0.21 & 0.41 \\
\hline Self-ass. health: Fair & 12,834 & 0.35 & 0.48 & 9,804 & 0.31 & 0.46 & 3,030 & 0.46 & 0.5 \\
\hline Self-ass. health: Poor & 12,834 & 0.18 & 0.39 & 9,804 & 0.15 & 0.35 & 3,030 & 0.31 & 0.46 \\
\hline Low level of school & 12,834 & 0.47 & 0.50 & 9,804 & 0.39 & 0.49 & 3,030 & 0.74 & 0.44 \\
\hline Medium level of school & 12,834 & 0.32 & 0.47 & 9,804 & 0.37 & 0.48 & 3,030 & 0.15 & 0.36 \\
\hline High level of school & 12,834 & 0.21 & 0.41 & 9,804 & 0.24 & 0.42 & 3,030 & 0.11 & 0.32 \\
\hline Blue collar worker & 12,834 & 0.19 & 0.40 & 9,804 & 0.25 & 0.43 & 3,030 & 0.01 & 0.11 \\
\hline White collar worker & 12,834 & 0.33 & 0.47 & 9,804 & 0.43 & 0.5 & 3,030 & 0.01 & 0.11 \\
\hline Trainee & 12,834 & 0.07 & 0.25 & 9,804 & 0.09 & 0.28 & 3,030 & 0 & 0.02 \\
\hline Unemployed & 12,834 & 0.06 & 0.24 & 9,804 & 0.08 & 0.27 & 3,030 & 0 & 0.04 \\
\hline Retired & 12,834 & 0.28 & 0.45 & 9,804 & 0.07 & 0.26 & 3,030 & 0.96 & 0.2 \\
\hline No job & 12,834 & 0.07 & 0.25 & 9,804 & 0.08 & 0.27 & 3,030 & 0.01 & 0.12 \\
\hline SHI mandatory member & 12,834 & 0.53 & 0.50 & 9,804 & 0.63 & 0.48 & 3,030 & 0.21 & 0.41 \\
\hline SHI voluntary member & 12,834 & 0.08 & 0.27 & 9,804 & 0.09 & 0.29 & 3,030 & 0.03 & 0.18 \\
\hline SHI family member & 12,834 & 0.13 & 0.34 & 9,804 & 0.16 & 0.37 & 3,030 & 0.04 & 0.19 \\
\hline SHI other member & 12,834 & 0.25 & 0.44 & 9,804 & 0.11 & 0.32 & 3,030 & 0.72 & 0.45 \\
\hline
\end{tabular}




\section{Results and discussion}

In the following, we first discuss the results for individuals age 65 and younger. Afterwards, we analyze potential differences for individuals older than 65 . Table 5 shows the marginal effects and significance levels of the exogenous regressors on the demand for hospital and dental SuppHI for the full model (Model II and Model IV) for all individuals below 65. In order to assess the robustness ${ }^{17}$ and to better identify the impact of the main drivers on the demand for supplemental health insurance, we also estimate reduced models (Model I and Model III) in which we only include the variables gender, age, household income (log), and individual health status as approximated by the indicator variable Sick in 2009.

We are able to investigate our adverse selection hypothesis only for hospital benefits because the SOEP does not include any information on dental health. We test the hypothesis in two ways: we first follow Schokkaert et al. (2010) and include the health indicator in the demand equation (Table 5). In a second step, we run the Cohen-Siegelman test, where we regress coverage on the health indicator (Table 6). In the reduced Model I for individuals aged 65 and younger, we find that the sickness indicator is statistically significant at the $5 \%$ level, supporting the adverse selection hypothesis: the likelihood of SuppHI is higher for those who have a chronic illness. In the full model, the indicator Sick in 2009 is significant at the $10 \%$ level. ${ }^{18}$ We find only small deviations from the full model in terms of marginal effects for the sickness indicator in the hospital model. When an individual has at least one of the above listed diseases, the likelihood of having hospital SuppHI increases by $1.45 \%$ (vs. 1.18\% in the full model), which indicates the existence of adverse selection for individuals age 65 and younger. The differences are not sufficiently high to assume a severe robustness issue. As mentioned above, previous studies that have examined the SOEP dataset have concluded that there is no adverse selection in the demand for supplemental hospital insurance (Kapfer, 2008).

\footnotetext{
${ }^{17}$ Variance inflation index (VIF) in the full model did not exceed a value of two for any variable used in the regression, which indicates no multicollinearity issues.

${ }^{18}$ When only considering the compulsory insured in the next section, significance is again at the $5 \%$ level for the full model; see table 2 .
} 
Table 5: Probit Regression (Marginal Effects) on Supplemental Hospital and Dental Insurance for Individuals Age 65 and Younger (N=9,804), 2008 (SOEP v25)

\begin{tabular}{|c|c|c|c|c|c|c|c|c|c|c|c|c|}
\hline \multirow{3}{*}{ Variables of interest } & \multicolumn{6}{|c|}{$\operatorname{Pr}($ hospital supplemental coverage) } & \multicolumn{6}{|c|}{$\operatorname{Pr}$ (dental supplemental coverage) } \\
\hline & \multicolumn{3}{|c|}{ Model I } & \multicolumn{3}{|c|}{ Model II } & \multicolumn{3}{|c|}{ Model III } & \multicolumn{3}{|c|}{ Model IV } \\
\hline & & & & & & & & & & & & \\
\hline Household income (log) & 0.0738 & $* * *$ & 0.0054 & 0.0634 & $* * *$ & 0.0118 & 0.0772 & $*$ & 0.0070 & 0.0696 & $* * *$ & 0.0154 \\
\hline Sick in 2009 & 0.0145 & $* *$ & 0.0064 & 0.0118 & $*$ & 0.0061 & 0.0139 & $* * *$ & 0.0081 & 0.0107 & & 0.0078 \\
\hline Life insurance & & & & 0.0316 & $* * *$ & 0.0056 & & & & 0.0632 & $* * *$ & 0.0072 \\
\hline Change of SHI provider & & & & 0.0278 & $* *$ & 0.0122 & & & & 0.0605 & $* * *$ & 0.0163 \\
\hline \multicolumn{13}{|l|}{ Control variables } \\
\hline Male & -0.0093 & * & 0.0055 & -0.0080 & & 0.0058 & -0.0262 & $* * *$ & 0.0071 & -0.0258 & $* * *$ & 0.0076 \\
\hline Age: younger than 25 & -0.0428 & $* * *$ & 0.0070 & -0.0396 & $* * *$ & 0.0088 & -0.0717 & $* * *$ & 0.0096 & -0.0535 & $* * *$ & 0.0130 \\
\hline Age: $26-35$ & 0.0195 & $* *$ & 0.0089 & 0.0018 & & 0.0080 & 0.0285 & $* * *$ & 0.0115 & 0.0054 & & 0.0107 \\
\hline Age: $46-55$ & -0.0091 & & 0.0072 & -0.0131 & $*$ & 0.0068 & -0.0008 & $* * *$ & 0.0098 & -0.0110 & & 0.0094 \\
\hline Age: $56-65$ & 0.0043 & & 0.0084 & -0.0002 & & 0.0092 & 0.0135 & $* * *$ & 0.0111 & 0.0032 & & 0.0121 \\
\hline $\mathrm{BMI}$ & -0.0020 & $* * *$ & 0.0006 & -0.0012 & $*$ & 0.0006 & -0.0008 & $* * *$ & 0.0008 & 0.0002 & & 0.0008 \\
\hline Household size & & & & -0.0180 & $* * *$ & 0.0027 & & & & -0.0324 & $* * *$ & 0.0037 \\
\hline Risk attitude & & & & -0.0048 & & 0.0177 & & & & -0.0025 & & 0.0227 \\
\hline Risk attitude *income & & & & 0.0006 & & 0.0022 & & & & 0.0005 & & 0.0029 \\
\hline Hospital stay in t-1 & & & & 0.0042 & & 0.0094 & & & & & & \\
\hline Low level of school & & & & -0.0218 & $* * *$ & 0.0065 & & & & -0.0346 & $* * *$ & 0.0084 \\
\hline High level of school & & & & 0.0270 & $* * *$ & 0.0076 & & & & 0.0092 & & 0.0092 \\
\hline Blue collar worker & & & & -0.0097 & & 0.0072 & & & & -0.0211 & $* *$ & 0.0091 \\
\hline Trainee & & & & 0.0141 & & 0.0162 & & & & -0.0107 & & 0.0184 \\
\hline Unemployed & & & & -0.0076 & & 0.0138 & & & & -0.0402 & $* * *$ & 0.0151 \\
\hline Retired & & & & -0.0028 & & 0.0140 & & & & -0.0076 & & 0.0176 \\
\hline No job & & & & 0.0100 & & 0.0125 & & & & -0.0172 & & 0.0144 \\
\hline SHI voluntary member & & & & 0.0104 & & 0.0090 & & & & -0.0030 & & 0.0114 \\
\hline SHI family member & & & & -0.0114 & & 0.0089 & & & & -0.0294 & $* * *$ & 0.0115 \\
\hline SHI other member & & & & -0.0085 & & 0.0116 & & & & -0.0171 & & 0.0148 \\
\hline Log-likelihood & $-2,851.86$ & & & $-2,758.02$ & & & $-3,969.12$ & & & $-3,814.03$ & & \\
\hline
\end{tabular}


In contrast to previous studies, we split the data into two subgroups at the age of 65 and use actual sickness data to estimate individuals' heath status, ${ }^{19}$ whereas other studies relied on previous hospital stays and self-reported health to estimate the individual health status. We include hospital stays in the previous period in Model II and find no statistically significant impact. Model IX (Table 14 in the Appendix) shows that using self-rated health status, as has been typical in previous studies, shows no significant impact. Accordingly, this finding suggests that we have access to more detailed health-related data compared with previous studies.

Table 6: Cohen-Siegelman Test for Adverse Selection: Probit Regression on Health Status for Individuals Age 65 and Younger ( $N=9,804), 2008$ (SOEP v25)

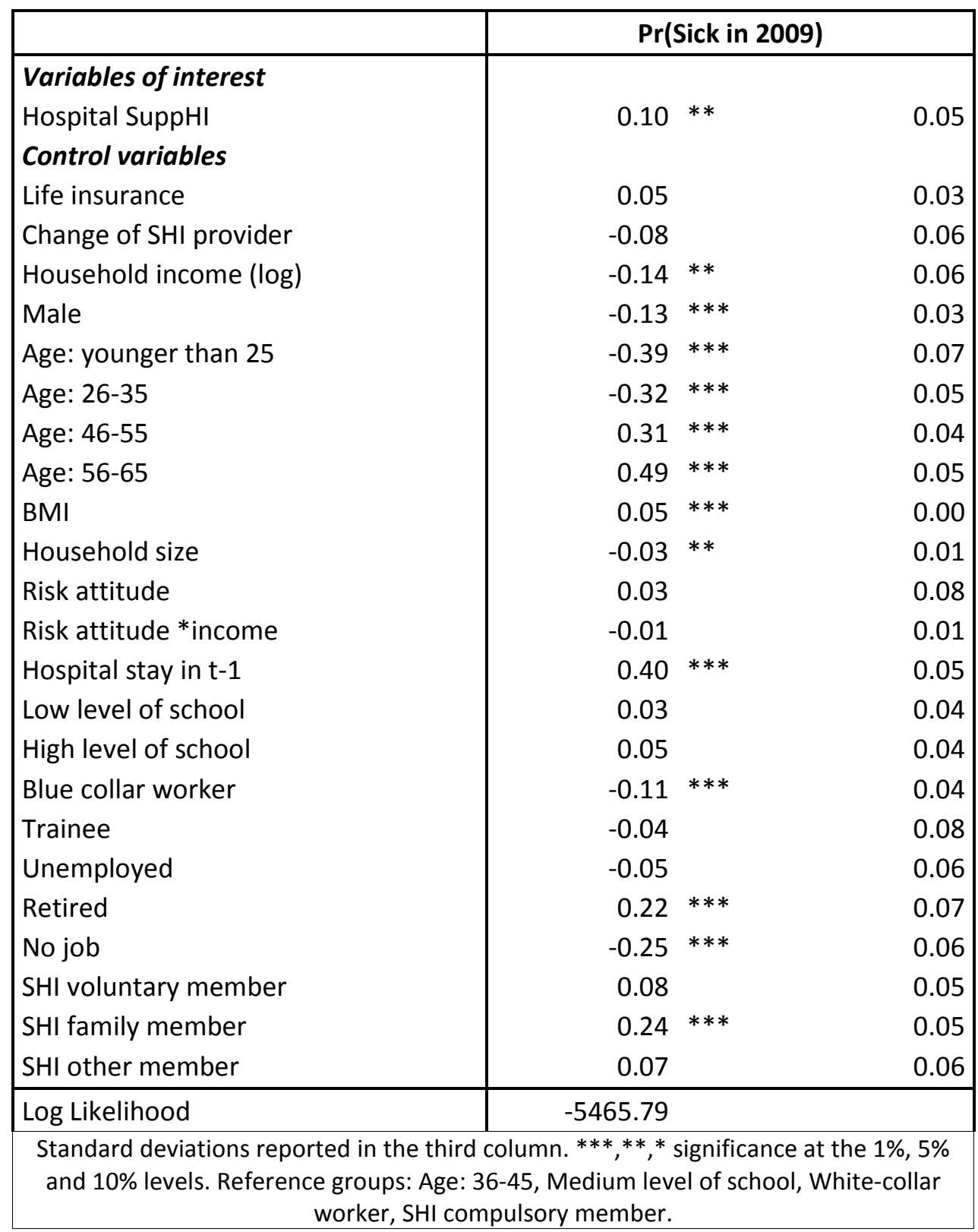

\footnotetext{
${ }^{19}$ Actual sickness was included in the SOEP in 2009 for the first time. Data on self-reported health and medical service intensity were available previously.
} 
To underline our findings, we run the Cohen-Siegelman test for adverse selection. We find that having hospital SuppHI increases the likelihood of suffering from the above-defined chronic conditions (Table 6). This finding is significant at the $5 \%$ level and is in line with our adverse selection hypothesis.

We subsequently investigate our insurance affinity hypothesis. Holding life insurance is highly significant in both lines of SuppHI and has a positive impact, implying that holding life insurance increases the demand for hospital and dental SuppHI. The marginal effect for hospital insurance is $3.16 \%$, and it is $6.32 \%$ for dental insurance; that is, the effect for dental SuppHI is twice as great as that for hospital SuppHI. Our insurance affinity factor measures whether an individual has life insurance, which is a purely financial policy. It would appear to be straightforward that our factor has higher explanatory power for dental SuppHI because this policy closes financial coverage gaps compared with the more quality-oriented hospital SuppHI.

The insurance affinity hypothesis is further supported by the fact that having changed SHI provider in the last period increases the likelihood of having both types of SuppHI. Individuals who change their sickness fund can be expected to have spent some effort in designing their health insurance according to their needs, which suggests that they have carefully exploited options to add on to the public coverage.

With respect to our income hypothesis, household income (log) has a positive and significant impact on the likelihood of holding hospital SuppHI as shown, e.g., by Schokkaert et al. (2010) and Kapfer (2008). The marginal effect for a one-unit increase in the logarithmic household income increases the likelihood of having hospital SuppHI by $7.38 \%$ in the reduced model and $6.34 \%$ in the full model. An increase from the median income of $€ 3,000$ to the 75 th percentile $(€ 3,850)$ increases the likelihood of having hospital SuppHI by $1.84 \%$ (Model I) or 1.58\% (Model II).

Models III and IV illustrate how logarithmic household income affects the demand for dental SuppHI for individuals below 65. Marginal effects are equal to $7.72 \%$ and $6.96 \%$ in the full and reduced models, respectively. We do not, however, find support for our hypothesis that income is a more important driver for quality-oriented hospital insurance compared with dental coverage that aims at covering out-of-pocket expenses in our dataset of individuals below 65 .

With respect to the control variables, we see no statistically significant impact of gender for hospital benefits in the full model. In Model I, the likelihood of holding hospital SuppHI for men is slightly less and significant at the $10 \%$ level. This is comparable with the findings of Schokkaert et al. (2010), who also do not find a statistically significant impact of gender in their full model. With respect to dental benefits, there is a consistent statistical significance at the $1 \%$ level in both models that men are less likely to hold dental SuppHI. We find that younger individuals are statistically signif- 
icantly less likely to hold hospital and dental SuppHI, which supports the findings of Kapfer (2008). Self-stated risk attitudes for both hospital and dental SuppHI are not statistically significant. ${ }^{20}$

A higher level of education increases the likelihood of holding both types of SuppHI, as shown by Ettner (1997), ${ }^{21}$ and household size decreases the likelihood, which is different from the findings from the Belgian study by Schokkaert et al. (2010). BMI is statistically significant at the $10 \%$ level for hospital benefits; higher BMI decreases the likelihood of holding SuppHI. All other controls are not statistically significant for hospital benefits. For dental SuppHI, we see that the demand depends more on socioeconomic factors such as occupational status and not primarily on income. We find that unemployed individuals and blue-collar workers are significantly less likely to hold dental SuppHI. In addition, family members, who do not have to pay any premiums in the SHI system, are less likely to have dental SuppHI.

Table 7 displays the marginal effects for the demand for hospital SuppHI for individuals aged 66 and older. As before, we fit Model I with a reduced set of exogenous regressors and Model II including all variables. We do not, however, estimate the demand for dental SuppHI for individuals aged 66 (seniors) and older because dentures are by far the most common medical prosthesis. ${ }^{22}$ Dentures are covered by German SHI with coinsurance rates between $50 \%$ and $65 \%$.

In contrast to the results for individuals younger than 66 , the sickness indicator has a negative sign for seniors, implying that sicker individuals are less likely to hold SuppHI. This finding is significant at the $10 \%$ level in Model V and at the $5 \%$ level in the full model (Model VI). We attribute this change of sign to the hypothesis that private information diminishes over the course of a lifetime. For seniors, it can be suspected that most potential conditions have already materialized and therefore, the insurers' underwriting will capture them. Accordingly, we do not find evidence of adverse selection for seniors. We rather confirm Kapfer's (2008) hypothesis of risk selection by the insurers, and this finding is also confirmed by the Cohen-Siegelman test, the result of which was that the coefficient for holding hospital SuppHI is negative and significant at the $5 \%$ level (Table 8 ).

\footnotetext{
${ }^{20}$ We do not find significant effects of gender or risk attitude when accounting for the different perceptions of risk among male and female individuals by introducing the interaction of male and risk attitude (see Table 9 in the Appendix).

${ }^{21}$ These findings are in line with those from previous studies (Berghman and Meerbergen, 2005; Kapfer, 2008; Vargas and Elhewaihi, 2008; Schokkaert et al., 2010).

${ }^{22}$ See Institut der Zahnaerzte (2005). Only $2.6 \%$ of all individuals aged 65 and older had tooth implants.
} 
Table 7: Probit Regression (Marginal Effects) on Supplemental Hospital Insurance for Individuals Age 66 and Older ( $N=3,030), 2008$ (SOEP v25)

\begin{tabular}{|c|c|c|c|c|c|c|}
\hline \multirow[b]{3}{*}{ Variables of interest } & \multicolumn{6}{|c|}{ Pr(hospital supplemental coverage) } \\
\hline & \multicolumn{3}{|c|}{ Model V } & \multicolumn{3}{|c|}{ Model VI } \\
\hline & & & & & & \\
\hline Household income (log) & 0.1166 & $* * *$ & 0.0102 & 0.1079 & $* * *$ & 0.0164 \\
\hline Sick2009 & -0.0170 & $*$ & 0.0102 & -0.0179 & $* *$ & 0.0090 \\
\hline Life insurance & & & & 0.0211 & * & 0.0108 \\
\hline Change of sickness fund & & & & -0.0224 & & 0.0262 \\
\hline \multicolumn{7}{|l|}{ Control variables } \\
\hline Male & -0.0249 & $* * *$ & 0.0090 & -0.0233 & $* * *$ & 0.0082 \\
\hline Age: $76-85$ & 0.0011 & & 0.0105 & -0.0039 & $* *$ & 0.0089 \\
\hline Age: Older than 85 & 0.0361 & & 0.0276 & 0.0219 & $*$ & 0.0223 \\
\hline BMI & -0.0030 & $* * *$ & 0.0012 & -0.0007 & & 0.001 \\
\hline Household size & & & & -0.0494 & $* * *$ & 0.0089 \\
\hline Risk attitude & & & & 0.01309 & & 0.0238 \\
\hline Risk attitude *income & & & & -0.0010 & & 0.0031 \\
\hline Hospital stay in t-1 & & & & 0.01986 & $*$ & 0.0117 \\
\hline Low level of school & & & & -0.0791 & $* * *$ & 0.0154 \\
\hline High level of school & & & & 0.0080 & & 0.0130 \\
\hline Blue collar worker & & & & 0.1554 & & 0.1278 \\
\hline Retired & & & & 0.03217 & $*$ & 0.0165 \\
\hline No job & & & & 0.10207 & & 0.1103 \\
\hline SHI voluntary member & & & & 0.01921 & & 0.0228 \\
\hline SHI family member & & & & -0.01771 & & 0.0169 \\
\hline SHI other member & & & & 0.00242 & & 0.0099 \\
\hline Log Likelihood & -751.98 & & & -747.67 & & \\
\hline
\end{tabular}

Among the seniors, holding life insurance and changing the SHI provider have less explanatory power to predict the demand for hospital SuppHI. The first finding can be explained by the fact that the predominant life insurance products in the German market are term policies and endowment policies, which are not offered to individuals who exceed certain age thresholds. ${ }^{23}$ The summary statistics show that individuals older than 65 are three times less likely to change their SHI provider. Table 7 still shows strong support for our income hypothesis. In addition, the likelihood of holding hospital SuppHI decreases with household size as well as low education levels compared with the subsample of individuals younger than 65 .

\footnotetext{
${ }^{23}$ Check24.de (an online comparison tool) does not show any available policies for individuals older than 65 .
} 
Table 8: Cohen-Siegelman Test for Adverse Selection: Probit Regression on Health Status for Individuals Age 66 and Older ( $N=3,030), 2008$ (SOEP v25)

\begin{tabular}{|c|c|c|c|}
\hline & \multicolumn{3}{|c|}{$\operatorname{Pr}($ Sick in 2009) } \\
\hline \multicolumn{4}{|l|}{ Variable of interest } \\
\hline Hospital SuppHI & -0.2195 & $* *$ & 0.0899 \\
\hline \multicolumn{4}{|l|}{ Control variables } \\
\hline Life insurance & 0.0613 & & 0.0618 \\
\hline Change of SHI provider & -0.1293 & & 0.2003 \\
\hline Household income (log) & 0.0199 & & 0.1034 \\
\hline Male & -0.0128 & & 0.0525 \\
\hline Age: $76-85$ & 0.4205 & $* * *$ & 0.0591 \\
\hline Age: Older than 85 & 0.2092 & $*$ & 0.1232 \\
\hline BMI & 0.0551 & $* * *$ & 0.0065 \\
\hline Household size & -0.0377 & & 0.0496 \\
\hline Risk attitude & -0.0499 & & 0.1605 \\
\hline Risk attitude *income & 0.0055 & & 0.0212 \\
\hline Hospital stay in t-1 & 0.2690 & $* * *$ & 0.0669 \\
\hline Low level of school & -0.0466 & & 0.0727 \\
\hline High level of school & -0.0452 & & 0.0982 \\
\hline Blue collar worker & -0.2836 & & 0.3085 \\
\hline Unemployed & -1.4183 & $*$ & 0.8315 \\
\hline Retired & -0.0395 & & 0.2325 \\
\hline No job & -0.5150 & & 0.3179 \\
\hline SHI voluntary member & 0.4021 & $* * *$ & 0.1539 \\
\hline SHI family member & 0.0837 & & 0.1505 \\
\hline SHI other member & 0.1132 & $*$ & 0.0607 \\
\hline Log Likelihood & -1766.11 & & \\
\hline \multicolumn{4}{|c|}{$\begin{array}{c}\text { Standard deviations reported in third column. }{ }^{* * * * *}, * \text { significance at the } 1 \%, 5 \% \text { and } 10 \% \\
\text { levels. Reference groups: Age: } 66-75, \text { Medium level of school, White-collar worker, SHI } \\
\text { compulsory member. Occupational category of trainee dropped. }\end{array}$} \\
\hline
\end{tabular}

In the next section, we first analyze the age effect and adverse selection and then check the robustness of the above explained findings concerning adverse selection, insurance affinity, and the income hypothesis by fitting the models on data subsets as well as using variations of the independent variables to control for measurement errors. 


\section{Robustness of the Results}

\subsection{Age Effect and Adverse Selection}

We find that there is a notable difference in the demand for SuppHI regarding adverse selection in the two subsamples of non-retirees $(n=9,804)$ and individuals above 65 years $(n=3,030)$. Whereas we find positive and significant marginal effects in our sickness variable for hospital SuppHI in the sample of individuals age 65 and younger (Table 5), the effect reverses in the subsample of individuals above age 65 (Table 7). We attribute this effect to the idea that private information on the individual health status diminishes with age.

Table 9: Cohen-Siegelman Test for Adverse Selection: Probit Regression on Health Status for All Individuals ( $\mathrm{N}=12,834), 2008$ (SOEP v25)

\begin{tabular}{|c|c|c|c|}
\hline & & $\operatorname{Pr}($ Sick in 2009) & \\
\hline \multicolumn{4}{|l|}{ Variables of interest } \\
\hline Hospital SuppHI & 0.0106 & & 0.0164 \\
\hline \multicolumn{4}{|l|}{ Control variables } \\
\hline Life insurance & 0.0187 & $*$ & 0.0105 \\
\hline Change of SHI provider & -0.0294 & & 0.0213 \\
\hline Household income (log) & -0.0269 & & 0.0189 \\
\hline Male & -0.0357 & $* * *$ & 0.0102 \\
\hline Age: younger than 25 & -0.1386 & $* * *$ & 0.0232 \\
\hline Age: $26-35$ & -0.1150 & $* * *$ & 0.0162 \\
\hline Age: $46-55$ & 0.1203 & $* * *$ & 0.0152 \\
\hline Age: 56-65 & 0.1912 & $* * *$ & 0.0182 \\
\hline Age: $66-75$ & 0.2165 & $* * *$ & 0.0256 \\
\hline Age: $76-85$ & 0.3565 & $* * *$ & 0.0264 \\
\hline Age: older than 85 & 0.2644 & $* * *$ & 0.0487 \\
\hline BMI & 0.0193 & $* * *$ & 0.0011 \\
\hline Household size & -0.0143 & $* * *$ & 0.0053 \\
\hline Risk attitude & 0.0242 & & 0.0276 \\
\hline Risk attitude *income & -0.0037 & & 0.0036 \\
\hline Hospital stay in t-1 & 0.1410 & $* * *$ & 0.0152 \\
\hline Low level of school & 0.0115 & & 0.0119 \\
\hline High level of school & 0.0161 & & 0.0140 \\
\hline Blue collar worker & -0.0445 & $* * *$ & 0.0144 \\
\hline Trainee & -0.0154 & & 0.0300 \\
\hline Unemployed & -0.0180 & & 0.0230 \\
\hline Retired & 0.0863 & $* * *$ & 0.0232 \\
\hline No job & -0.0828 & $* * *$ & 0.0219 \\
\hline SHI voluntary member & 0.0393 & $* *$ & 0.0186 \\
\hline SHI family member & 0.0906 & $* * *$ & 0.0186 \\
\hline SHI other member & 0.0307 & $* *$ & 0.0155 \\
\hline Log Likelihood & -7262.2542 & & \\
\hline
\end{tabular}


To isolate this effect, we first run the limited and full models for hospital SuppHI on the overall sample of individuals age 18 to $99(n=12,834)$ (Table 9). We do not find a significant impact of being sick on holding SuppHI.

In a second step, we introduce interactions of our health indicator variable Sick in 2009 and the different age groups (Table 10). ${ }^{24}$ We find that the sickness indicator remains significant and the marginal effect increases in size to $2.51 \%$ in the reduced model (Model VII) and to $2.09 \%$ in the full model (Model VIII) compared with the subsample of individuals age 65 and younger (Table 5). The impact of age on the demand for SuppHI does not change substantially compared with the two subsamples, showing slightly higher marginal effects in older age groups. We do not find significant effects for the interaction between sickness and age for age groups below 65 compared with the omitted category of being sick and aged 36-45; for individuals aged $66-85$, we find significant negative marginal effects for the interaction. Being diagnosed with a chronic disease in 2009 and being 66 to 75 years of age reduces the probability of holding supplemental hospital benefits by $4.35 \%$ in the reduced model and $3.87 \%$ in the full model. Equally, the interaction of being sick in 2009 and being in the age interval of 76 to 85 years leads to a reduction in the marginal effect of $3.59 \%$ in both models. We do not find a significant marginal effect for individuals age 86 and older, but we partially attribute this to the smaller sample size of this population and the ongoing natural selection process in this age group as well as the limited availability of SuppHI. These findings underline our previous argument that supplemental hospital insurance suffers from adverse selection for non-retired individuals. It diminishes for individuals above 66 years because private information on health status resolves given that most illnesses materialize over time.

The marginal effects of all socioeconomic determinants do not change substantially. Similarly, the results of Table 9 are in line with our previous findings regarding the insurance affinity and income hypothesis.

\footnotetext{
${ }^{24}$ Summary statistics for the overall sample can be found in the first columns of Table 1 and Table 4.
} 
Table 10: Probit Regression (Marginal Effects) on Supplemental Hospital for All Individuals ( $N=12,834), 2008$ (SOEP v25)

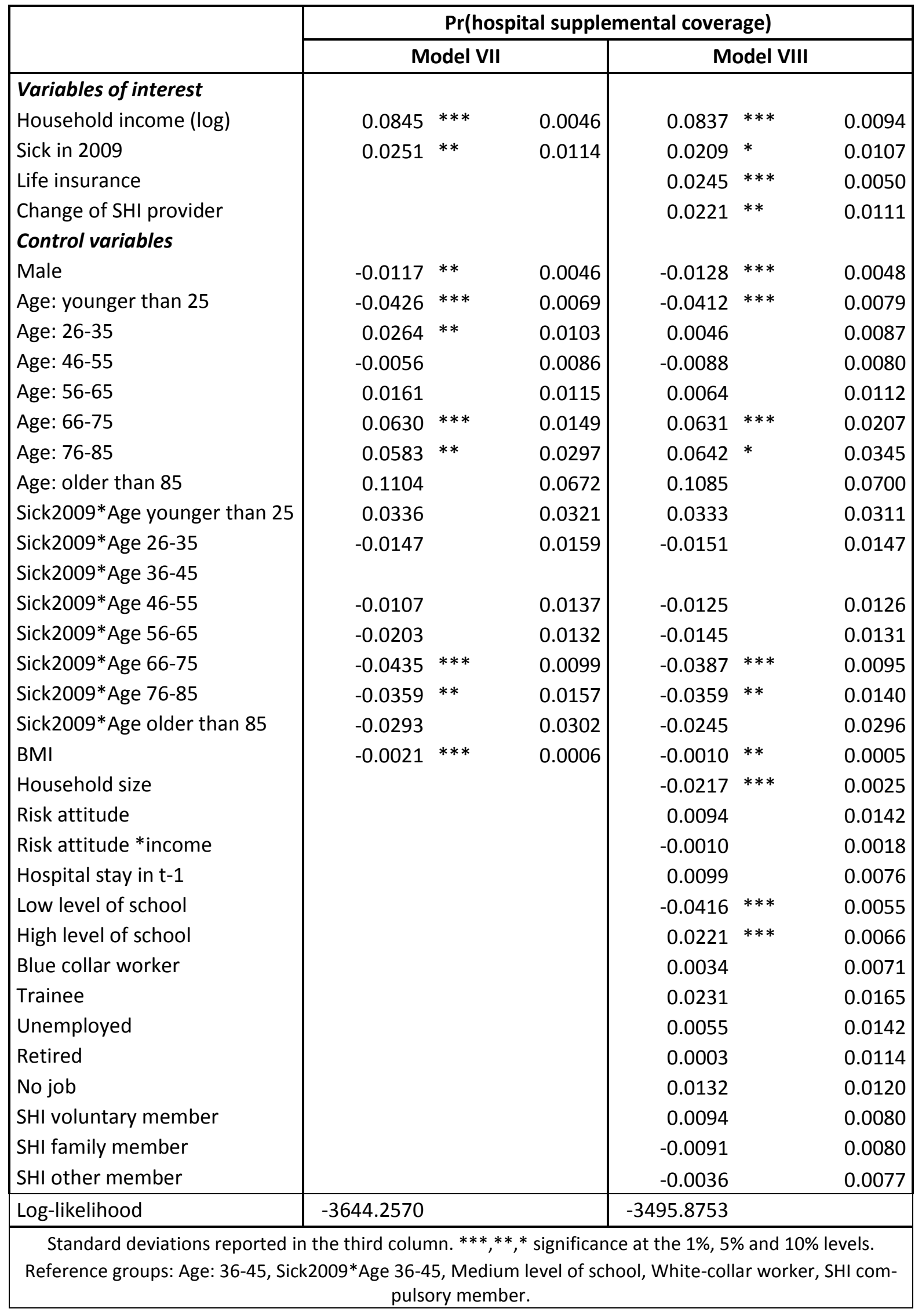




\subsection{Different Subsamples}

We run our regressions on a different subset in order to assess the robustness of our results. In the subset, we only include individuals who are mandatory, premium-paying members in the $\mathrm{SHI} .{ }^{25}$ The full dataset also includes voluntary SHI members who could theoretically opt out of SHI and seek private coverage. ${ }^{26}$ Because the German private health insurance industry conducts risk-based underwriting, those who remain voluntarily in $\mathrm{SHI}$ are assumed to be higher-risk types compared with the averages in their income classes. The privately insured have to pay premiums for each family member under an individual health insurance plan, whereas SHI members can insure spouses and children free of charge if their dependents do not have any earnings that are subject to social security contributions. Staying in SHI as a voluntary member is supposedly attractive to large households because of the possibility of insuring non-contributory family members under SHI. A t-test for the groups of compulsory insured and voluntary SHI members indicates that there is no evidence for a selection issue; household size does not significantly differ between the two groups; nor do we find a significant increase in chronic diseases (Sick in 2009) among voluntary insured SHI members. ${ }^{27}$ In order to check whether a potential sample selection issue problem could have skewed the results, we created a subsample with only premium-paying, mandatory members (Table 11). In 2008, individuals could opt out SHI or become voluntary members if their earnings exceeded $€ 48,150$ for three consecutive years. Accordingly, the subset will not be representative in terms of income distribution, but we can verify the robustness of the adverse selection and insurance affinity results. Table 11 shows the regressions for hospital (Model IX) and dental (Model X) SuppHI. In this subset, we dropped the controls for type of employment because the sample is much more homogenous in this sense. In terms of our adverse selection hypothesis, we still find that the sickness indicator is significant at the $10 \%$ level for hospital insurance, but it is not significant for dental insurance. The marginal effect of the sickness indicator for hospital SuppHI is equal to $1.52 \%$, which is relatively similar to the effect from the full dataset (1.18\%).

Holding life insurance is significant at the $1 \%$ level for hospital and dental insurance, and the marginal effects equal $3.27 \%$ and $7.18 \%$, respectively. This compares with $3.16 \%$ and $6.32 \%$, respectively, in the full dataset, and thus, the differences are minimal. The impact of changing the SHI provider in the previous period remains positive and significant compared with the full model for hospital and dental benefits. The marginal effect scarcely differs in size in both lines of insurance, equaling 4.07\% and $8.07 \%$ compared with $2.78 \%$ and $6.05 \%$ in the full model. We suggest that changing the SHI provider has a greater impact on the demand for hospital and dental SuppHI for compulsory insured individuals because changing one's SHI provider must be initiated by the compulsory insured

\footnotetext{
${ }^{25}$ Sample statistics for the subsample of compulsory insured can be found in the Appendix.

${ }^{26}$ In addition, there are also family members and other members who are mostly retirees.

${ }^{27}$ See Figure 2 and Figure 3 in the Appendix.
} 
and not by any family members who are under the same coverage. Thus, the fact that a compulsory insured changes the SHI provider implies that she has actively sought information about her health insurance status. In comparison, a family member may simply change the SHI provider as the associated compulsory insured has.

Table 11: Probit Regression (Marginal Effects) on Supplemental Hospital and Dental Insurance for Compulsory Insured Only (N=6,216), 2008 (SOEP v25)

\begin{tabular}{|c|c|c|c|c|c|c|}
\hline & \multicolumn{3}{|c|}{ Pr(hospital SuppHI) } & \multicolumn{3}{|c|}{ Pr(dental SuppHI) } \\
\hline & \multicolumn{3}{|c|}{ Model IX } & \multicolumn{3}{|c|}{ Model X } \\
\hline Varmabies of interest & & & & & & \\
\hline Household income (log) & 0.0765 & $* * *$ & 0.0170 & 0.0924 & $* * *$ & 0.0222 \\
\hline Sick2009 & 0.0152 & * & 0.0080 & 0.0143 & & 0.0105 \\
\hline Life insurance & 0.0327 & $* * *$ & 0.0071 & 0.0718 & $* * *$ & 0.0094 \\
\hline Change of SHI provider & 0.0407 & $* *$ & 0.0160 & 0.0807 & $* * *$ & 0.0213 \\
\hline \multicolumn{7}{|l|}{ Control variables } \\
\hline Male & -0.0150 & $* *$ & 0.0071 & -0.0401 & $* * *$ & 0.0095 \\
\hline Age: younger than 25 & -0.0269 & $* *$ & 0.0110 & -0.0574 & $* * *$ & 0.0150 \\
\hline Age: 26-35 & 0.0088 & & 0.0100 & 0.0084 & & 0.0134 \\
\hline Age: 46-55 & -0.0127 & & 0.0086 & -0.0066 & & 0.0121 \\
\hline Age: $56-65$ & -0.0120 & & 0.0108 & -0.0066 & & 0.0153 \\
\hline BMI & -0.0009 & & 0.0008 & 0.0001 & & 0.0010 \\
\hline Household size & -0.0207 & $* * *$ & 0.0035 & -0.0345 & $* * *$ & 0.0048 \\
\hline Risk attitude & 0.0047 & & 0.0258 & 0.0176 & & 0.0335 \\
\hline Risk attitude *income & -0.0005 & & 0.0032 & -0.0021 & & 0.0042 \\
\hline Hospital stay in t-1 & -0.0034 & & 0.0117 & & & \\
\hline Low level of school & -0.0203 & $* *$ & 0.0082 & -0.0334 & $* *$ & 0.0111 \\
\hline High level of school & 0.0340 & $* * *$ & 0.0099 & 0.0396 & $* *$ & 0.0127 \\
\hline Log Likelihood & $-1,788.66$ & & & -669.60 & & \\
\hline
\end{tabular}

In a second robustness check, we account for changing individual family structures by introducing the adjusted household income per family member. Table 12 displays that the impact of per capita income is still significant at the $1 \%$ level for hospital and dental SuppHI. Household size is no longer significant for hospital benefits but significant at the $10 \%$ level for dental SuppHI. This allows for the conclusion that part of the household size impact is now included in the per capita income variable. All other estimates have the same significance levels and roughly the same size marginal effects. 
Table 12: Probit Regression (Marginal Effects) on Supplemental Hospital and Dental Insurance with Per Capita Income (N=9,804), 2008 (SOEP v25)

\begin{tabular}{|c|c|c|c|c|c|c|}
\hline & $\operatorname{Pr}($ hosp & tal Su & $\mathrm{pHH})$ & $\operatorname{Pr}(\mathrm{d}$ & ental S & \\
\hline & & del XI & & & Model & \\
\hline Variables of interest & & & & & & \\
\hline Per capita income (log) & 0.0594 & $* * *$ & 0.0112 & 0.0606 & $* * *$ & 0.0147 \\
\hline sick2009 & 0.0114 & $*$ & 0.0061 & 0.0104 & & 0.0078 \\
\hline Life insurance & 0.0326 & $* * *$ & 0.0055 & 0.0646 & $* * *$ & 0.0072 \\
\hline Change of SHI provider & 0.0286 & $* *$ & 0.0123 & 0.0615 & $* * *$ & 0.0163 \\
\hline Control variables & & & & & & \\
\hline Male & -0.0088 & & 0.0059 & -0.0269 & $* * *$ & 0.0076 \\
\hline Age: younger than 25 & -0.0395 & $* * *$ & 0.0088 & -0.0535 & $* * *$ & 0.0130 \\
\hline Age: $26-35$ & 0.0025 & & 0.0080 & 0.0061 & & 0.0108 \\
\hline Age: 46-55 & -0.0127 & $*$ & 0.0069 & -0.0102 & & 0.0094 \\
\hline Age: $56-65$ & 0.0006 & & 0.0092 & 0.0048 & & 0.0122 \\
\hline BMI & -0.0011 & $*$ & 0.0006 & 0.0003 & & 0.0008 \\
\hline Household size & 0.0035 & & 0.0042 & -0.0096 & $*$ & 0.0056 \\
\hline Risk attitude & -0.0172 & & 0.0158 & -0.0215 & & 0.0204 \\
\hline Risk attitude *income & 0.0021 & & 0.0020 & 0.0029 & & 0.0026 \\
\hline Hospital stay in t-1 & 0.0052 & & 0.0095 & & & \\
\hline Low level of school & -0.0217 & $* * *$ & 0.0065 & -0.0345 & $* * *$ & 0.0084 \\
\hline High level of school & 0.0259 & $* * *$ & 0.0076 & 0.0084 & & 0.0092 \\
\hline Blue collar worker & -0.0090 & & 0.0072 & -0.0208 & $* *$ & 0.0092 \\
\hline Trainee & 0.0138 & & 0.0162 & -0.0114 & & 0.0184 \\
\hline Unemployed & -0.0070 & & 0.0139 & -0.0402 & $* * *$ & 0.0151 \\
\hline Retired & -0.0025 & & 0.0141 & -0.0075 & & 0.0176 \\
\hline No job & 0.0105 & & 0.0126 & -0.0167 & & 0.0145 \\
\hline SHI voluntary member & 0.0100 & & 0.0090 & -0.0034 & & 0.0114 \\
\hline SHI family member & -0.0110 & & 0.0089 & -0.0292 & $* *$ & 0.0115 \\
\hline SHI other member & -0.0088 & & 0.0115 & -0.0177 & & 0.0147 \\
\hline Log Likelihood & $-2,758.47$ & & & $-3,815.84$ & & \\
\hline
\end{tabular}




\section{Conclusion}

In our paper, we determine factors that drive the demand for different types of SuppHI using a very rich dataset. We find that insurance affinity and income have a strong positive effect on the demand for SuppHI. Unlike previous studies that used SOEP data (Kapfer, 2008; Schmitz, 2011), we find evidence for adverse selection in SuppHI in Germany when we include data on individuals' actual health states as assessed by doctor-diagnosed diseases as opposed to self-reported health states or doctor visits. This is, however, only valid for individuals age 65 and younger. In contrast, we find support for the risk selection hypothesis of Kapfer (2008) for individuals aged 66 and older. These findings are in line with the assumptions of Peter et al. (2014) that private information diminishes over time when more and more diseases become apparent. When comparing the results for hospital and dental benefits, we find largely the same effects. However, we find that socioeconomic status independent of income, such as occupational status and type of SHI, has a significant impact on the demand for dental benefits but that the demand for hospital coverage primarily depends on income, insurance affinity, household size, and health status.

The strong dependence of SuppHI demand on income may raise equity or fairness issues concerning access to health insurance and medical care, especially when public benefits are further reduced. For now, SuppHI in Germany complements and enhances SHI coverage in terms of improved quality, as in the case of supplemental hospital benefits, and supplemental dental insurance does indeed substitute SHI benefits given that those have been cut over time. Our findings imply that comprehensive dental benefits are more often covered for higher-income individuals. Furthermore, the findings of adverse selection show that depending on age group, SuppHI policyholders can be healthier or sicker than the average population.

Given the recent developments in the German health insurance system, we believe that there is great potential for market growth in SuppHI. In addition, the acquired knowledge on the demand for different types of SuppHI provides valuable insights into how to design a reformed health care system that partially relies on SuppHI and that aims at ensuring that everyone receives appropriate care. The obtained results can be of importance for countries other than Germany. We observe that many countries with publicly provided coverage or social health insurance tend to cut benefits and incentivize the use of private supplemental insurance. 


\section{Appendix}

Table 13: Summary statistics of variables in the subsample of compulsory insured (age 65 and younger), 2008 (SOEP v25)

\begin{tabular}{|l|ccc|}
\hline Variables & Obs. & Mean & $\sigma$ \\
\hline Dependent variables & & & \\
Hospital benefits & 6,216 & 0.10 & 0.29 \\
Dental benefits & 6,216 & 0.16 & 0.37 \\
Variables of interest & & & \\
Household income (log) & 6,216 & 7.87 & 0.49 \\
Sick in 2009 & 6,216 & 0.30 & 0.46 \\
Life insurance & 6,216 & 0.64 & 0.48 \\
Change of SHI provider & 6,216 & 0.07 & 0.25 \\
Control Variables & & & \\
Male & 6,216 & 0.48 & 0.50 \\
Age & 6,216 & 42.44 & 11.46 \\
Age: younger than 25 & 6,216 & 0.08 & 0.28 \\
Age: 26-35 & 6,216 & 0.21 & 0.40 \\
Age: 36-45 & 6,216 & 0.29 & 0.45 \\
Age: 46-55 & 6,216 & 0.27 & 0.45 \\
Age: 56-65 & 6,216 & 0.15 & 0.35 \\
BMI & 6,216 & 25.96 & 4.59 \\
Household size & 6,216 & 2.79 & 1.22 \\
Monthly net income & 6,216 & $2,917.29$ & $1,397.39$ \\
Risk attitude & 6,216 & 4.53 & 2.22 \\
Hospital stay in t-1 & 6,216 & 0.09 & 0.28 \\
Self-ass. health: Very good & 6,216 & 0.09 & 0.29 \\
Self-ass. health: Good & 6,216 & 0.47 & 0.50 \\
Self-ass. health: Fair & 6,216 & 0.31 & 0.46 \\
Self-ass. health: Poor & 6,216 & 0.13 & 0.33 \\
Low level of school & 6,216 & 0.36 & 0.48 \\
Medium level of school & 6,216 & 0.43 & 0.49 \\
High level of school & 6,216 & 0.21 & 0.41 \\
Blue collar worker & 6,216 & 0.33 & 0.47 \\
White collar worker & 6,216 & 0.53 & 0.50 \\
Trainee & 6,216 & 0.05 & 0.21 \\
Unemployed & 6,216 & 0.04 & 0.19 \\
Retired & 6,216 & 0.04 & 0.18 \\
No job & 6,216 & 0.03 & 0.16 \\
\hline
\end{tabular}


Table 14: Probit Regression (Marginal Effects) on Supplemental Hospital Insurance with SelfAssessed Health Status (SAHS) ( $\mathrm{N}=9,804), 2008$ (SOEP v25)

\begin{tabular}{|c|c|c|c|}
\hline & \multicolumn{3}{|c|}{$\operatorname{Pr}$ (HospitalSuppHI) } \\
\hline & \multicolumn{3}{|c|}{ Model XIII } \\
\hline Variables of interest & & & \\
\hline Household income (log) & 0.0626 & $* * *$ & 0.0118 \\
\hline SAHS (very good) & 0.0043 & & 0.0121 \\
\hline SAHS (good) & 0.0080 & & 0.0087 \\
\hline SAHS (fair) & 0.0067 & & 0.0090 \\
\hline Life insurance & 0.0317 & $* * *$ & 0.0056 \\
\hline Change of SHI provider & 0.0272 & $* *$ & 0.0122 \\
\hline \multicolumn{4}{|l|}{ Control variables } \\
\hline Male & -0.0087 & & 0.0058 \\
\hline Age: younger than 25 & -0.0405 & $* * *$ & 0.0087 \\
\hline Age: $26-35$ & 0.0005 & & 0.0079 \\
\hline Age: 46-55 & -0.0117 & $*$ & 0.0069 \\
\hline Age $56-65$ & 0.0020 & & 0.0093 \\
\hline BMI & -0.0009 & & 0.0006 \\
\hline Household size & -0.0182 & $* * *$ & 0.0027 \\
\hline Risk attitude & -0.0048 & & 0.0177 \\
\hline Risk attitude *income & 0.0006 & & 0.0022 \\
\hline Hospital stay in t-1 & 0.0069 & & 0.0097 \\
\hline Low level of school & -0.0215 & $* * *$ & 0.0065 \\
\hline High level of school & 0.0273 & $* * *$ & 0.0076 \\
\hline Blue collar worker & -0.0100 & & 0.0072 \\
\hline Trainee & 0.0144 & & 0.0162 \\
\hline Unemployed & -0.0072 & & 0.0139 \\
\hline Retired & -0.0012 & & 0.0143 \\
\hline No job & 0.0091 & & 0.0125 \\
\hline SHI voluntary member & 0.0106 & & 0.0091 \\
\hline SHI family member & -0.0109 & & 0.0089 \\
\hline SHI other member & -0.0080 & & 0.0116 \\
\hline Log Likelihood & $2759.4800^{-}$ & & \\
\hline $\begin{array}{r}\text { Standard deviations repor } \\
10 \% \text { levels. Reference gro } \\
\text { Medium level of }\end{array}$ & $\begin{array}{l}\text { lumn. } * * *, * * \\
\text { health statu } \\
\text { ar worker, St }\end{array}$ & & $\begin{array}{l}5 \% \text { and } \\
36-45\end{array}$ \\
\hline
\end{tabular}




\section{References}

Abbring JH, Heckman JJ, Chiappori PA, Pinquet J. 2003. Adverse Selection and Moral Hazard in Insurance: Can Dynamic Data Help to Distinguish? Journal of the European Economic Association 1(2-3): 512-521.

Association of German Private Healthcare Insurers. 2010. Financial report for private healthcare insurance 2009/2010. Cologne.

Association of German Private Healthcare Insurers. 2012. Financial report for private healthcare insurance 2012. Cologne.

Bauer JM, Schiller J, Schreckenberger C. 2015. Heterogeneous Selection in the Market for Private Supplemental Dental Insurance: Evidence from Germany. Working Paper, University of Hohenheim. http://ssrn.com/abstract=2559293.

Berghman J, Meerbergen E. 2005. Supplementary Social Provisions in Second and Third Pillar Health Care. Research Project AG/01/084. Centre for Sociological Research. Leuven.

Bolhaar J, Lindeboom M, van der Klaauw B. 2012. A dynamic analysis of the demand for health insurance and health care. European Economic Review 56(4): 669-690.

Borrell C, Fernandez E, Schiaffino A, Benach J, Rajmil L, Villalbi JR, Segura A. 2001. Social class inequalities in the use of and access to health services in Catalonia, Spain: what is the influence of supplemental private health insurance. International Journal for Quality in Health Care 13(2): 117-125.

Briys E, Schlesinger H. 1990, Risk Aversion and the Propensities for Self Insurance and Self Protection. Southern Economic Journal 57(2): 458-467.

Browne MJ. 1992. Evidence of Adverse Selection in the Individual Health Insurance Market. Journal of Risk and Insurance 59(1): 13-33.

Browne MJ, Doerpinghaus H. 1994. Asymmetric Information and the Demand for Medigap Insurance. Inquiry 31(4): 445-450.

Chiappori PA, Salanié B. 2000. Testing for Asymmetric Information in Insurance Markets. Journal of Political Economy 108(1): 56-78.

Christoph B. 2003. Soziale Sicherheit im Krankheitsfall. Objektive Charakteristika und subjektive Einstellungen zur Gesundheit von Personen mit zusätzlicher privater Absicherung gegen Gesundheitsrisiken. Opladen.

Cohen A. 2005. Asymmetric Information and Learning: Evidence from the Automobile Insurance Market. Review of Economic and Statistics 87(2): 197-207.

Cohen A, Siegelman P. 2010. Testing for adverse selection in insurance markets. Journal of Risk and Insurance 77(1): 39-84.

Crossley TF, Kennedy S. 2002. The Reliability of Self-Assessed Health Status. Journal of Health Economics 21(4): 643-658. 
Dardanoni V, Donni PL. 2012. Incentive and selection effects of Medigap insurance on inpatient care. Journal of Health Economics 31(3): 457-470.

Dionne G, Eeckhoudt L. 1985. Self Insurance, Self Protection and Increased Risk Aversion. Economics Letters 17: 39-42.

Dionne G, Gourieroux C, Vanasse C. (2001). Testing for evidence of adverse selection in the automobile insurance market: A comment. Journal of Political Economy 109: 444-453.

Dohmen T, Falk A, Huffmann D, Sunde U, Schupp J, Wagner G. (2011). Individual Risk Attitudes. Measurement, Determinates and Behavioral Consequences. Journal of the European Economic Association 9(3): 522-550.

Ettner SL. 1997. Adverse selection and the purchase of Medigap insurance by the elderly. Journal of Health Economics 16(5): 543-562.

Fang H, Keane MP, Silverman D. 2008. Sources of Advantageous Selection: Evidence from the Medigap Insurance Market. Journal of Political Economy 116(2): 303 -350.

Finkelstein A, Poterba J. 2004. Adverse Selection in Insurance Markets: Policyholder Evidence from the U.K. Annuity Market 2004. Journal of Political Economy 112(1): 183-208.

Finkelstein A, McGarry K. 2006. Multiple dimensions of private information: Evidence from the longterm care insurance market. American Economic Review 96: 938-958.

Gardiol L, Geoffard, PY, Grandchamp C. 2011. Separating selection and incentive effects in health insurance. Working Paper, Paris Jourdan Sciences Economiques Series.

Garfinkel SA, Bonite AJ, McLeroy KR. 1987. Socioeconomic factors and Medicare supplemental health insurance. Health Care Financing Review 9(1): 21-30.

Goldman DP, Zissimopoulos JM. 2003. High Out-Of-Pocket Health Care Spending By The Elderly, Health Affairs 22(3): 194-202.

Holly A, Gardiol L, Domenighetti G, Bisig B. 1998. An econometric model of health care utilization and health insurance in Switzerland. European Economic Review 42(3-5): 513-522.

Institut der deutschen Zahnaerzte. 2005. Vierte Deutsche Studie zur Mundgesundheit. http://www.bzaek.de/fileadmin/PDFs/presse/dms/brosch.pdf [01 February 2015].

Kapfer J. 2008. Three Essays in Empirical Economics. Dissertation, Ludwig-Maximilians-Universität München: Volkswirtschaftliche Fakultät.

Kim H, Kim D, Im S, Hardin JW. 2009. Evidence of asymmetric information in the automobile insurance market: dichotomous versus multinomial measurement of insurance coverage. Journal of Risk and Insurance 76(2): 343-366.

Marquis MS, Phelps CE. 1987. Price Elasticity and Adverse Selection in the Demand for Supplementary Health Insurance. Economic Inquiry 25(2): 299-315. 
Ministry of Health. 2009. Statutory Health Insurance- Members, coinsured family members, and sickness leave, annual averages 1999 to 2008.

http://www.bmg.bund.de/fileadmin/redaktion/pdf_statistiken/krankenversicherung/KM1JD20 04-pdf-5112.pdf [01 February 2015].

McCall N, Rice T, Sangl J. 1986. Consumer knowledge of Medicare and supplemental health insurance benefits. Health Service Research 20(1): 633-657.

Nuscheler R, Knaus T. 2005. Risk Selection in the German Public Health Insurance System. Health Economics 14(12): 1253-1271.

Peter R, Richter A, Steinorth, P. 2014. Yes, No, Perhaps? Premium Risk and Guaranteed Renewable Insurance Contracts with Heterogeneous Private Information. Working Paper, LudwigMaximilians-Universität München.

Pauly MV. 1974. Overinsurance and Public Provision of Insurance: The Roles of Moral Hazard and Adverse Selection. Quarterly Journal of Economics 88(1): 44-62.

Pauly M, Kunreuther H, Hirth R. 1995. Guaranteed Renewability in Insurance. Journal of Risk and Uncertainty 10(2): 143-156.

Pourat N, Rice T; Kominski G, Snyder RE. 2000. Socioeconomic Differences in Medicare Supplemental Coverage. Health Affairs 19(5): 186-196.

Rothschild M, Stiglitz J. 1976. Equilibrium in Competitive Insurance Markets: An Essay on the Economics of Imperfect. Quarterly Journal of Economics 90(4): 629-649.

Saliba B, Ventelou B. 2007. Complementary health insurance in France Who pays? Why? Who will suffer from public disengagement? Health Policy 81(2-3): 166-182.

Schellhorn M. 2001. The effect of variable health insurance deductibles on the demand for physician visits. Health Economics 10(5): 441-456.

Schmitz, Hendrik (2011), Direct evidence of risk aversion as a source of advantageous selection in health insurance, Economic Letters, 113, pp. 180-82.

Schokkaert E, Van Outric T, De Graeve D, Lecluyse A, Van De Voorde C. 2010. Supplemental Health Insurance and Equality of Access in Belgium. Health Economics 19(4): 377-395.

Shmueli A. 2010. The Effect of Health on Acute Care Supplemental Insurance Ownership: An Empirical Analysis. Health Economics 19(4): 341-350.

Simon M. 2013. Das Gesundheitssystem in Deutschland, Eine Einführung in Struktur und Funktionsweise (4th ed.). Bern: Huber.

Socio-Economic Panel (SOEP). Data for years 1984-2008, version 25, SOEP, 2009, doi:10.5684/soep.v25.

Van de Ven WPMM, Schut FT. 2008. Universal Mandatory Health Insurance In The Netherlands: A Model For The United States? Health Affairs 27(3): 771-781. 
Vargas MH, Elhewaihi M. 2008. What is the impact of duplicate coverage on the demand for health care in Germany? Working Paper, Institute for Advanced Development Studies.

Vera-Hernandez AM. 1999. Duplicate coverage and demand for health care. The case of Catalonia. Health Economics 8(7): 579-598.

Wagner GG, Frick JR, Schupp J. 2007. The German Socio- Economic Panel Study (SOEP) - Evolution, Scope and Enhancements. Schmoller's Jahrbuch - Journal of Applied Social Science Studies 127(1): 139-169.

Werblow A, Felder S. 2003. Der Einfluss von freiwilligen Selbstbehalten in der gesetzlichen Krankenversicherung: Evidenz aus der Schweiz. Schmoller's Jahrbuch - Journal of Applied Social Science Studies 123(2): 235-264.

Wilson C. 1977. A model of Insurance Markets with Incomplete Information. Journal of Economic Theory 16(2): 167-207.

Woolfe JR, Goddeeris JH. 1991. Adverse selection, moral hazard, and wealth effects in the Medigap insurance market. Journal of Health Economics 10(4): 433-459.

Zavadil T. 2011. Do the better insured cause more damage? Testing for asymmetric information in car insurance. Working Paper, National Bank of Slovakia, Bratislava. 